\title{
AFIP-6 Characterization Summary Report
}

\author{
D. Keiser \\ J. Jue \\ J. Hess
}

December 2011

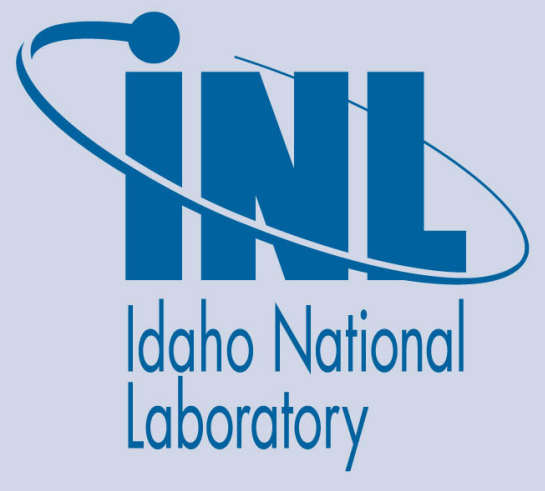

The INL is a U.S. Department of Energy National Laboratory operated by Battelle Energy Alliance 
INL/EXT-11-21090

\title{
AFIP-6 Characterization Summary Report
}

D. Keiser

J. Jue

J. Hess

December 2011

\section{Idaho National Laboratory \\ Idaho Falls, Idaho 83415}

http://www.inl.gov

\author{
Prepared for the \\ U.S. Department of Energy \\ Office of Nuclear Energy \\ Under DOE Idaho Operations Office \\ Contract DE-AC07-05ID14517
}




\section{DISCLAIMER}

This information was prepared as an account of work sponsored by an agency of the U.S. Government. Neither the U.S. Government nor any agency thereof, nor any of their employees, makes any warranty, expressed or implied, or assumes any legal liability or responsibility for the accuracy, completeness, or usefulness, of any information, apparatus, product, or process disclosed, or represents that its use would not infringe privately owned rights. References herein to any specific commercial product, process, or service by trade name, trade mark, manufacturer, or otherwise, does not necessarily constitute or imply its endorsement, recommendation, or favoring by the U.S. Government or any agency thereof. The views and opinions of authors expressed herein do not necessarily state or reflect those of the U.S. Government or any agency thereof. 



\title{
AFIP-6 Characterization Summary Report
}

\author{
INL/EXT-11-21090
}

December 2011

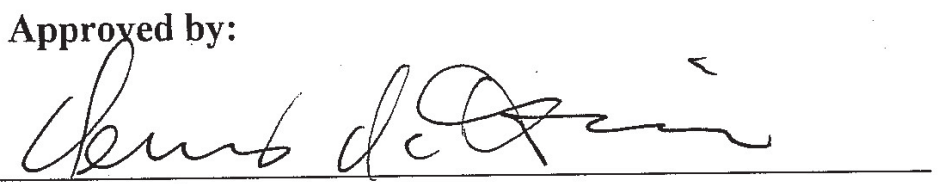

Dennis Keiser

GTRLGharacterization Lead

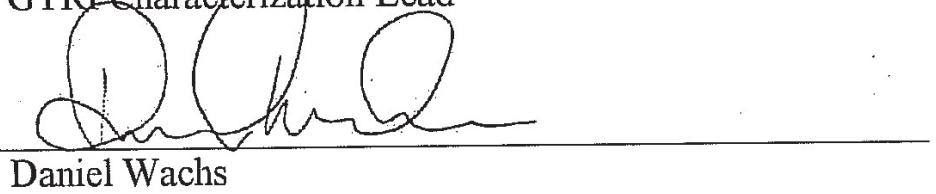

GTRI Technical Lead

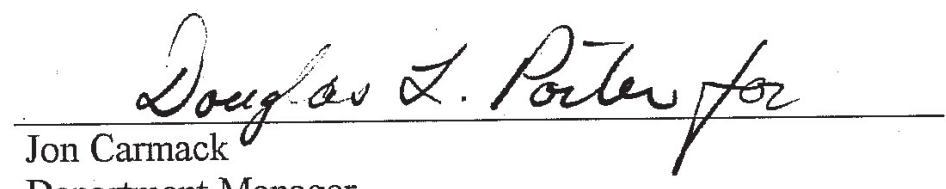

Department Manager
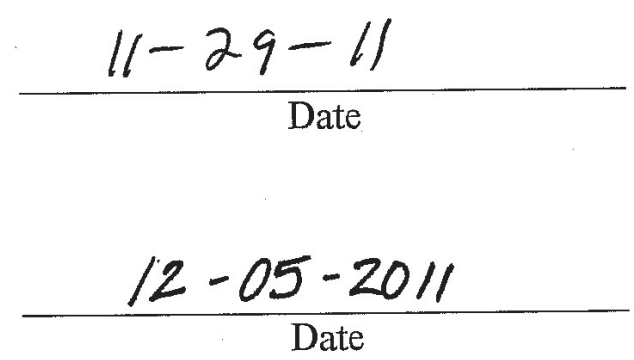

$11 \cdot 29 \cdot 2011$ 


\section{CONTENTS}

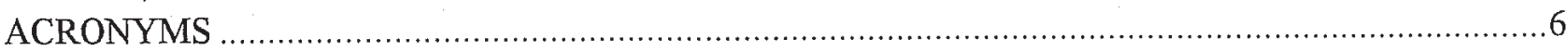

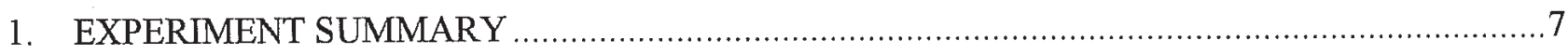

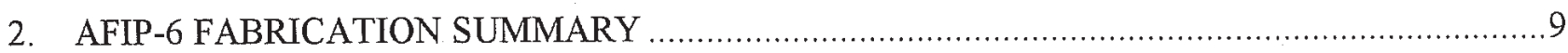

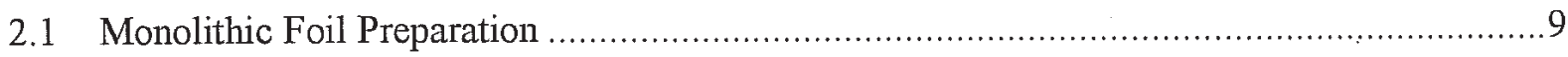

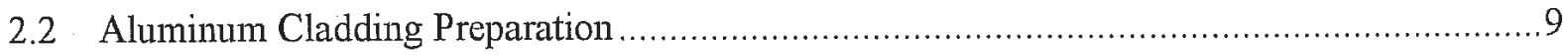

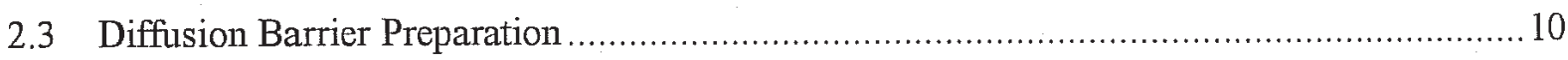

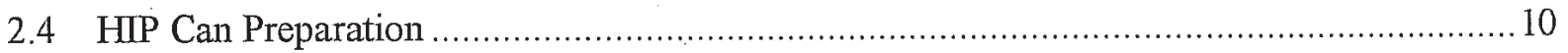

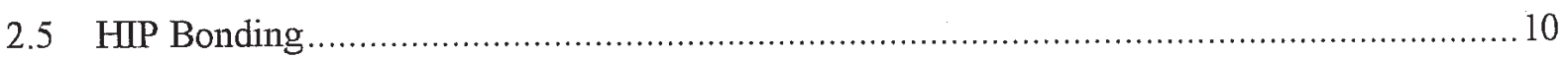

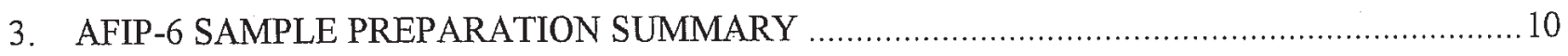

4. AFIP-6 MICROSCOPY CHARACTERIZATION SUMMARY …..................................... 11

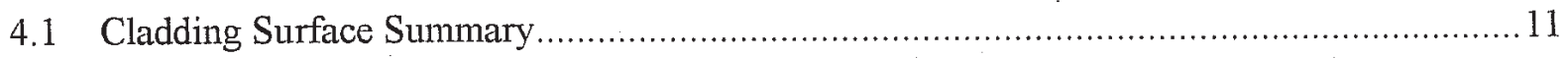

4.2 Cladding-to-Cladding Interface Summary .................................................... 13

4.3 Cladding-to-Zirconium Diffusion Barrier Interface Summary .................................. 14

4.4 Zirconium Diffusion Barrier-to-Fuel Foil Interface Summary ...................................... 16

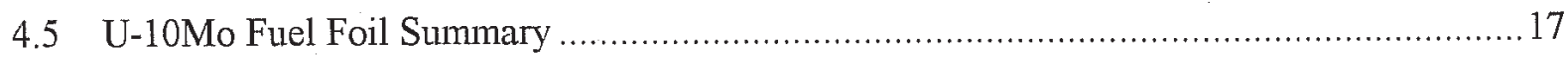

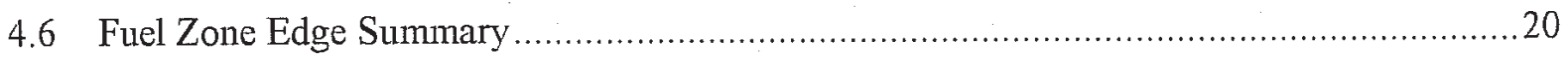

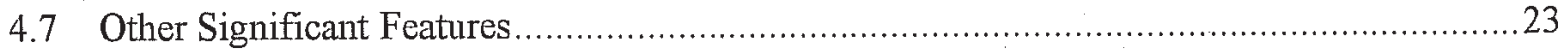

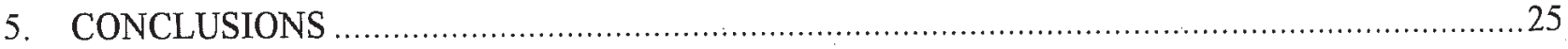

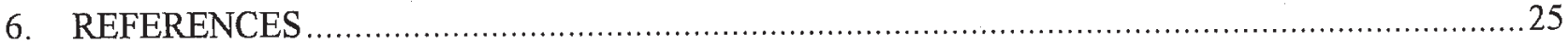




\section{FIGURES}

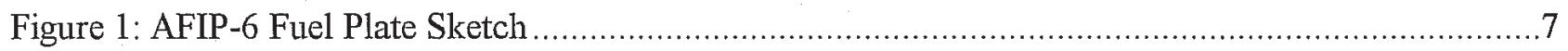

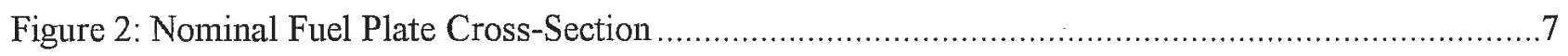

Figure 3: Rolling assembly with a zirconium diffusion barrier...............................................9

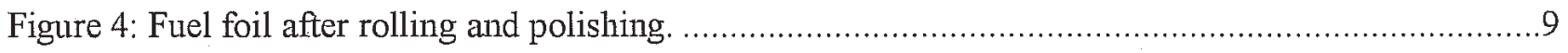

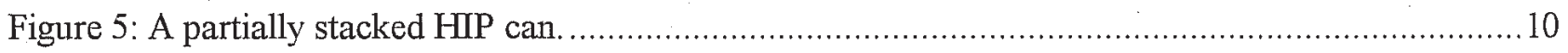

Figure 6: 50x-BSE - Low magnification SEM image of a fuel plate cross-section. ............................. 11

Figure 7: 1000x-BSE - SEM image of the cladding-to-epoxy interface. The oxide layer can be observed as the slightly darker area on the edge of the cladding......................................11

Figure 8: 5000x-BSE - High magnification SEM image of the cladding-to-epoxy interface with

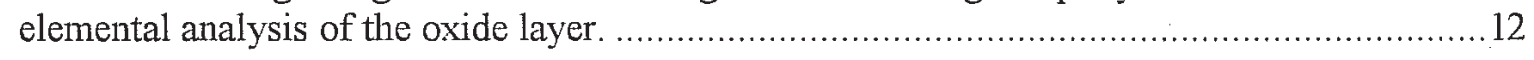

Figure 9: 5000x-BSE - High magnification SEM image and linescan analysis of the oxide layer...........13

Figure 10: 346-1-F16, 50x-BSE - SEM image of the cladding-to-cladding area at the end of the fuel zone. No clear bond line can be seen. The shearing process causes the curved end.........13

Figure 11: 346-1-F16, 200x-BSE: Low magnification SEM micrograph of the cladding-tocladding bond line.

Figure 12: JJ662, 500x-BSE - SEM micrograph with EDS/WDS of the cladding-to-cladding bond line. The absence of a solid line shows that good bonding occurred during the HIP process.

Figure 13: 346-1-F16, 2000x-BSE - High magnification SEM image of the cladding-to-diffusion barrier interface. An interaction layer can be observed between the two layers.

Figure 14: JJ662, 5000X-BSE - High magnification SEM image with EDS/WDS of the interaction layer between the cladding and diffusion barrier. Interaction layer is shown to be silicon rich

Figure 15: JJ662, 5000x-BSE - High magnification SEM image with EDS/WDS of the interaction layers between the zirconium diffusion barrier and fiel foil.

Figure 16: JJ662, 5000x-BSE - High magnification SEM image with linescan analysis of the diffusion barrier interfaces...

Figure 17: 346-1-F16, 50x-BSE - Low magnification SEM micrograph showing the cross-section of the fuel plate.

Figure 18: SEM image of the U-10 fuel foil. The large dark defects are carbides and oxides within the fuel. The larger, darker areas are fuel decomposition.

Figure 19: High magnification SEM image of the U-10Mo fuel foil. The dark region indicated in the fuel is decomposition......

Figure 20: BM814-F10, 1000x-BSE - SEM image with EDS/WDS of a defect within the U$10 \mathrm{Mo}$ fuel foil. Shown in a displacement of the zirconium diffusion barrier within the fuel foil.

Figure 21: JJ663-F16, 50x-BSE - Low magnification SEM image of the end of the fuel zone. The distortion of the end and high degree of interaction is due to the shearing of the fuel foil. 
Figure 22: BM811-F12, 100x-BSE - Low magnification SEM image of the end of the fuel zone. The high level of interaction and distortion of the end can be contributed to the shearing process. The cracking occurred during sample preparation process.

Figure 23: JJ662, 500x-BSE - SEM image with EDS/WDS of the cladding-to-zirconium and cladding-to- fuel foil interaction layers. Cracking can be seen within the interaction layer.

Figure 24: 346-1-F-16, 200x-BSE - SEM image and element mapping of the fuel foil end. Two interaction layers can be observed, a combination of $\mathrm{Zr} / \mathrm{Al}-6061$ and U-Mo/Al-6061....

Figure 26: JJ663-F11, 200x-BSE - Low magnification SEM image highlighting the indicated defect in the diffusion barrier. The defect appears to be a gap in the diffusion barrier....

Figure 27: JJ663-F11, 2500x-BSE/SE - High magnification SEM image of the crack present in the diffusion barrier. The defect appears to be the result of the foil shearing process pre-HIP as an interaction layer has formed along the fuel foil-to-diffusion barrier interface

Figure 28: BM814-F10, 500x-BSE - SEM image of a crack/delamination between the zirconium diffusion barrier and the cladding. .24

\section{TABLES}

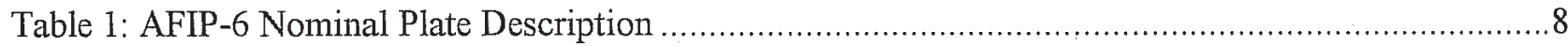

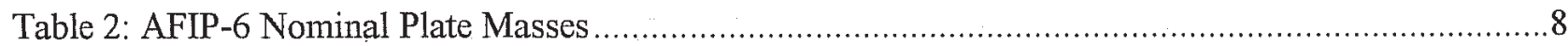

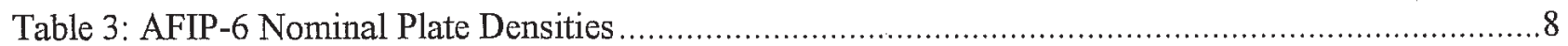

Table 4: Carbon Concentration of Representative U-Mo AFIP Fuel Fabricated at Y-12 .................... 17 


\section{ACRONYMS}

AFIP ATR full-size plate in center flux trap position

Al-6061 Common use aluminum alloy

ATR Advanced Test Reactor

CFT Center Flux Trap

EDS Energy Dispersive X-ray Spectroscopy

DU Depleted Uranium

FB Friction Bond

HEU High Enriched Uranium

HIP Hot Isostatic Press

INL Idaho National Lab

KSI Kilo-pounds per Square Inch

LEU Low Enriched Uranium

Mo Molybdenum

OM Optical Microscopy

RERTR Reduced Enrichment for Research and Test Reactors

SEM Scanning Electron Microscopy

TEM Transmission Electron Microscopy

U Uranium

U-Mo Uranium-Molybdenum Alloy

U-xMo Uranium-Molybdenum Alloy (" $x$ " denotes the wt.\% Mo in the alloy)

WDS Wavelength Dispersive Spectroscopy

$\mathrm{Zr} \quad$ Zirconium 


\section{AFIP-6 Characterization Summary Report \\ 1. EXPERIMENT SUMMARY}

The AFIP-6 (ㅅR Full -size-plate In center flux trap Position) experiment was designed to evaluate the performance of monolithic uranium-molybdenum (U-Mo) fuels at a scale prototypic of Advanced Test Reactor (ATR) fuel plates (45" long). The AFIP-6 test was the first test with plates that were swaged into the rails of the assembly. This test served to examine the effects of a plate in a swaged condition with longer fuel zones $(22.5 \%$ long), that were centered in the plate. AFIP-6 test plates employed a zirconium interlayer that was co-rolled with the fuel foil. Previous mini-plate and AFIP irradiation experiments performed in ATR have demonstrated the stable behavior of the interface between the U-Mo fuel and the zirconium interlayer.

Experiment design allowed the fuel plates to be tested in the Center Flux Trap (CFT) of the ATR using the existing AFIP test train hardware design. The AFIP train was oriented in accordance with markings on the test train hardware, the same as previous AFIP irradiations. The fuel plate assembly was planned for two fuel plates, one monolithic plate fabricated by the Friction Bonding (FB) process and one monolithic plate fabricated by the Hot Isostatic Press (HIP) process. The friction bonding process was not utilized for this experiment; instead both plates were fabricated using the HIP bonding process. A sketch of the fuel plate's critical dimensions is seen in Figure 1.

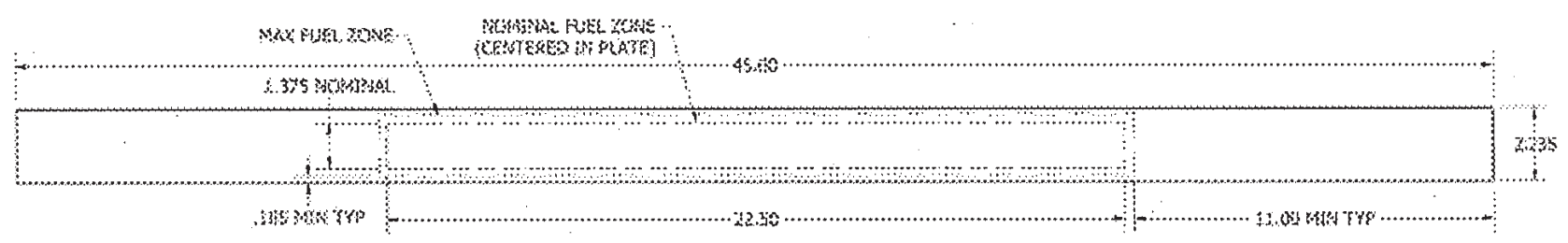

Figure 1: AFIP-6 Fuel Plate Sketch

The fuel phase in the AFIP-6 fuel plates is uranium 10wt.\% molybdenum (U-10Mo) alloy at 40\% U-235 enrichment. The enrichment was selected to achieve the desired irradiation condition: a peak surface heat flux of at least $500 \mathrm{~W} / \mathrm{cm}^{2}$. A zirconium diffusion barrier was applied to fuel material supplied by the Y12 National Security Complex. Nominal U-Mo thickness is 0.013 " with a 0.001 " zirconium interlayer on each side and nominal fuel plate thickness is 0.050 " as seen in Figure 2.

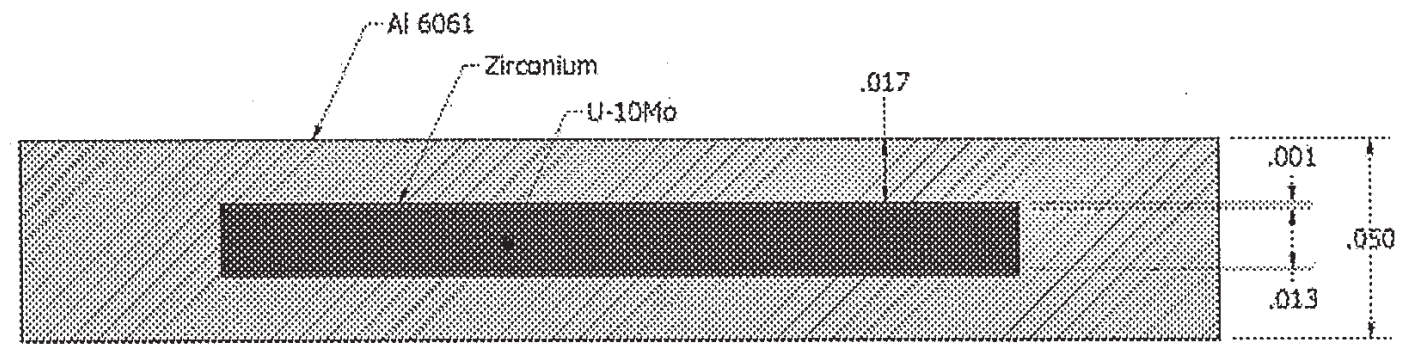

Figure 2: Nominal Fuel Plate Cross-Section 
Tables 1, 2, and 3 display the nominal fuel plate descriptions, masses, and densities respectively.

Table 1: AFIP-6 Nominal Plate Description

\begin{tabular}{|c|c|c|c|c|c|}
\hline Plate ID & Fuel Type & $\begin{array}{c}\text { Fuel Phase } \\
\text { Composition }\end{array}$ & $\begin{array}{c}\text { Fuel } \\
\text { Enrichment } \\
(\% \mathrm{U}-235)\end{array}$ & $\begin{array}{c}\text { Fuel } \\
\text { Thickness } \\
\text { (in) }\end{array}$ & $\begin{array}{c}\text { Interlayer } \\
\text { Phase }\end{array}$ \\
\hline $6 \mathrm{ZF}$ & Monolithic & U-10Mo & 40 & 0.013 & $\mathrm{Zr}$ \\
\hline $6 \mathrm{ZH}$ & Monolithic & U-10Mo & 40 & 0.013 & $\mathrm{Zr}$ \\
\hline
\end{tabular}

Table 2: AFIP-6 Nominal Plate Masses

\begin{tabular}{|c|c|c|c|c|c|c|c|}
\hline \multirow[b]{2}{*}{ Plate ID } & \multirow[b]{2}{*}{$\begin{array}{c}\text { Fuel Plate } \\
\text { Mass (g) }\end{array}$} & \multicolumn{4}{|c|}{ Fuel Phase Constituent Masses (g) } & \multirow{2}{*}{$\begin{array}{c}\text { Interlayer } \\
\text { Phase } \\
\text { Mass (g) } \\
\text { Zr }\end{array}$} & \multirow{2}{*}{$\begin{array}{l}\text { Cladding } \\
\text { Mass (g) } \\
\text { Al-6061 }\end{array}$} \\
\hline & & $\begin{array}{l}\text { U-Mo Fuel } \\
\text { Phase Total }\end{array}$ & Total U & $\mathrm{U}-235$ & Mo & & \\
\hline $6 Z F$ & 320.76 & 112.17 & 100.96 & 40.38 & 11.22 & 6.62 & 201.96 \\
\hline $6 \mathrm{ZH}$ & 320.76 & 112.17 & 100.96 & 40.38 & 11.22 & 6.62 & 201.96 \\
\hline Totals & 641.52 & 224.35 & 201.91 & 80.76 & 22.43 & 13.24 & 403.93 \\
\hline
\end{tabular}

Table 3: AFIP-6 Nominal Plate Densities

\begin{tabular}{|c|c|c|c|c|c|}
\hline \multicolumn{2}{|l|}{. } & \multicolumn{4}{|c|}{ Fuel Phase Constituent Densities (g/cc) } \\
\hline Plate D & $\begin{array}{c}\text { Fuel } \\
\text { Volume } \\
\text { (cc) }\end{array}$ & U-Mo Alloy & Total U & U-235 & Mo \\
\hline $6 Z \mathrm{~F}$ & 6.591 & 17.020 & 15.318 & 6.127 & 1.702 \\
\hline $6 \mathrm{ZH}$ & 6.591 & 17.020 & 15.318 & 6.127 & 1.702 \\
\hline
\end{tabular}




\section{AFIP-6 FABRICATION SUMMARY}

\subsection{Monolithic Foil Preparation}

U-10Mo coupons were supplied by Y-12 National Security Complex. The coupons were created by induction melting of the source materials (HEU, DU, Mo) into a uranium-molybdenum alloy with 10 wt. $\%$ molybdenum and $40 \%$ U-235 enrichment. The cast coupon received from Y-12 was machined into smaller coupons $\left(\sim 4.5^{\prime \prime} \mathrm{L} \times \sim 3.0\right.$ " $\mathrm{W} \times \sim 0.14$ " $\left.\mathrm{T}\right)$ to be used as the fuel meat in the AFIP-6 experiment. The coupons were placed in a picture frame rolling assembly after the corners and edges of the coupon were rounded to prevent the foil from breaching during the rolling process. The lids of the rolling assembly were affixed with a thin (.010" thick) sheet of zirconium tack welded directly to the assembly. The assembly was welded in an inert glove box forming the can.

The can was annealed at $650{ }^{\circ} \mathrm{C}$ after welding, to pre-heat the can prior to rolling. Between rolling passes the can would be returned to the box furnace at $650{ }^{\circ} \mathrm{C}$ for up to 15 minutes. The can was initially rolled perpendicular to the long direction (cross-rolling) to achieve a wide foil that could be sheared into two finished foils. After the cross-rolling step, the can resumed rolling parallel to the long direction of the can. Typical hot rolling procedure, the total time exposure to $650{ }^{\circ} \mathrm{C}$ was approximately 110 minutes. After reaching the target hot rolling thickness the foil was decanned and sheared in half lengthwise. The foils were then cold rolled to smooth out the variable fuel thickness variability. When the foils were at the desired cold rolling thickness they were cut to size, cleaned, and polished.

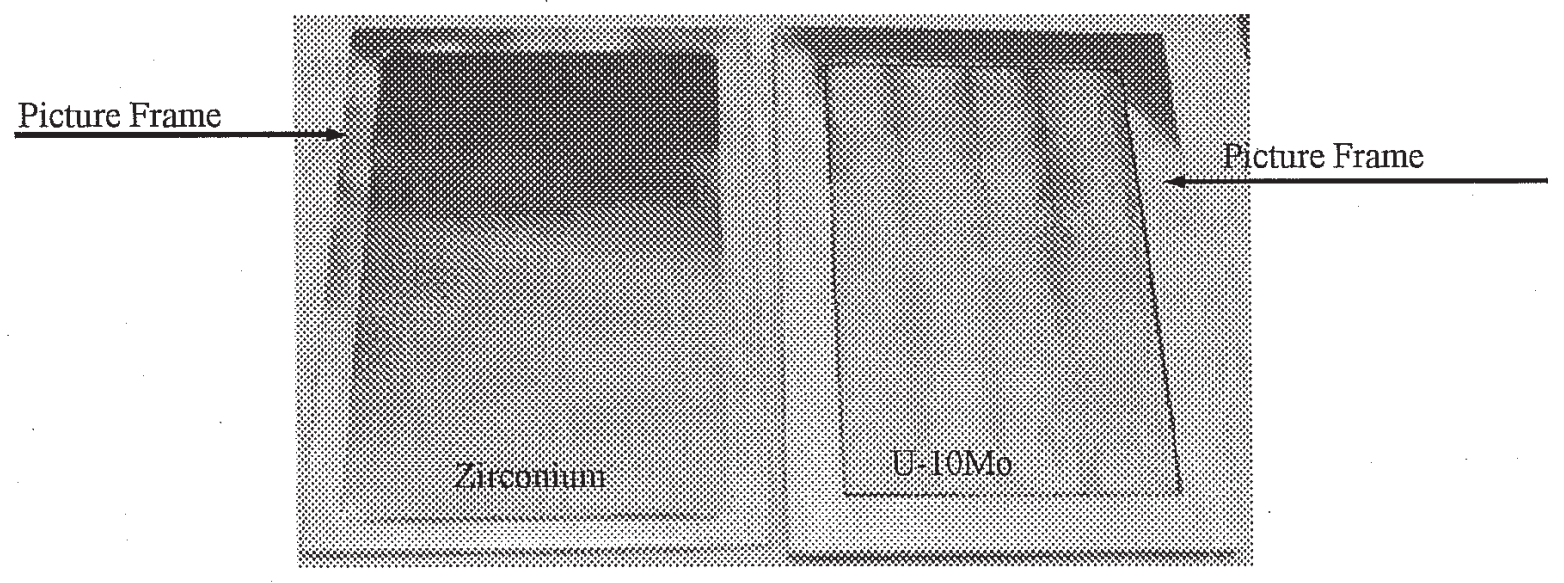

Figure 3: Rolling assembly with a zirconium diffusion barrier.

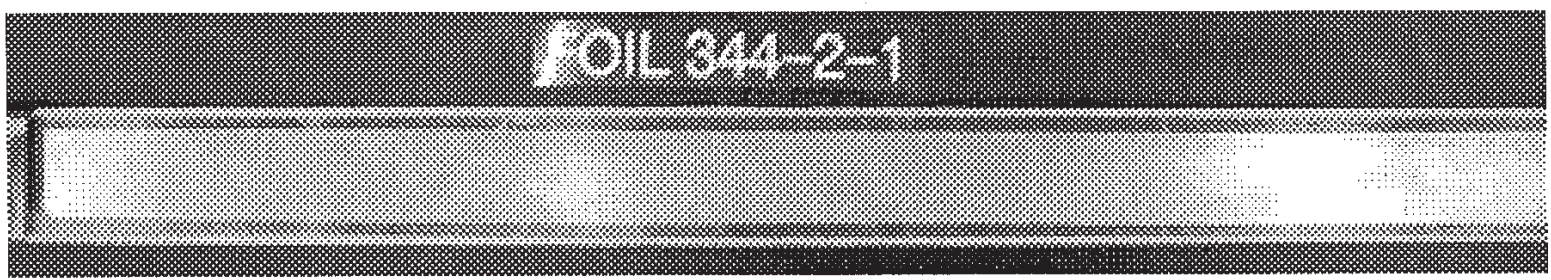

Figure 4: Fuel foil after rolling and polishing.

\subsection{Aluminum Cladding Preparation}

Cladding for the AFIP-6 experiment is Al-6061 alloy procured in the T6 condition. The aluminum received was 0.063 " thick and a 0.016 " deep pocket was milled into the aluminum for the fuel foil. Prior to assembly in the HIP can, the aluminum plates are cleaned with sodium hydroxide and nitric acid. 


\subsection{Diffusion Barrier Preparation}

A zirconium diffusion barrier between the fuel foil and cladding is used to address the fuel-tocladding interaction issue. Zirconium was chosen because of its compatibility with both aluminum and uranium in the temperatures encountered during both fabrication and irradiation. The diffusion barrier was co-rolled onto the fuel foil during the hot rolling process.

\subsection{HIP Can Preparation}

The HIP can was made from stainless steel. Prior to loading the can all components were cleaned thoroughly. Neolube coated steel "strong backs" are placed between the assembled fuel plates. These steel plates ensure uniform pressure is exerted on the fuel plates. After the fuel plates and steel "strong backs" have been placed into the HIP can, the assembly was welded together, leak checked with helium, and degassed at $321{ }^{\circ} \mathrm{C}$ for $2.75-3$ hours. After degassing the assembly was returned to room temperature while remaining under vacuum. After cooling, the evacuation tube was crimped and welded to retain the vacuum during the HIP bonding process.

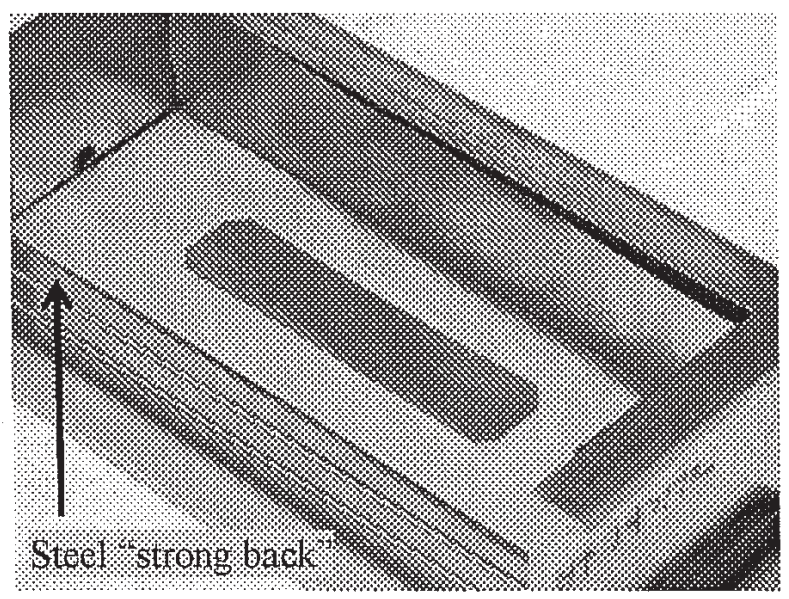

Figure 5: A partially stacked HIP can.

\subsection{HIP Bonding}

The HIP bonding was conducted at $\mathrm{B} \& \mathrm{~W}$ using the same processing parameters that have been using in previous fabrication work. The can underwent processing at $560^{\circ} \mathrm{C}\left(+0 /-12{ }^{\circ} \mathrm{C}\right)$ and a pressure of $15 \mathrm{ksi}(+/-1 \mathrm{ksi})$ for 95 minutes. The exact specifications are proprietary information of B\&W and are not provided to INL. After the HIP plates are removed they are examined using radiography to assess fuel position, ultrasonic testing (UT) to measure cladding thickness and identify debonds, and sheared to final size.

\section{AFIP-6 SAMPLE PREPARATION SUMMARY}

After HIP bonding, the plates were characterized by a through-transmission ultrasonic scanning unit (UT) for any indication of de-bonding. The plates were then sectioned as indicated in the cutting diagram, mounted in an epoxy filled MET mount, and rough polished to a 1200-grit sandpaper finish. Some samples were further polished to 1-micron surface finish using diamond suspension to expose the transverse cross-section. After this step the samples can be observed under an optical microscope (OM). Samples that are to be observed using a scanning electron microscopy (SEM) with Energy Dispersive Xray Spectrometry (EDS) and Wavelength Dispersive X-ray Spectrometry (WDS) detectors are sputter coated with a thin layer of palladium at $10 \mathrm{kV}$ for up to three minutes. 


\section{AFIP-6 MICROSCOPY CHARACTERIZATION SUMMARY}

\subsection{Cladding Surface Summary}

The oxide formation on the surface of the cladding is an important factor. The oxide is preformed after the HIP process in an autoclave. The AFIP- 6 archive plates exhibited the normal preformed oxide layer. Figure 6 is a low magnification SEM image cross section of the fuel plate mounted in epoxy. Figure 7 is a high magnification SEM image where the oxide layer can be clearly observed between the cladding and epoxy. Figure 8 is an SEM image that has had elemental analysis performed. The increased oxygen content indicates that the layer being analyzed is an oxide layer. Figure 9 is an SEM image with linescan analysis of the epoxy-to-cladding interface. The oxygen peak that can be observed in the spectra also confirms the oxide layer formation.

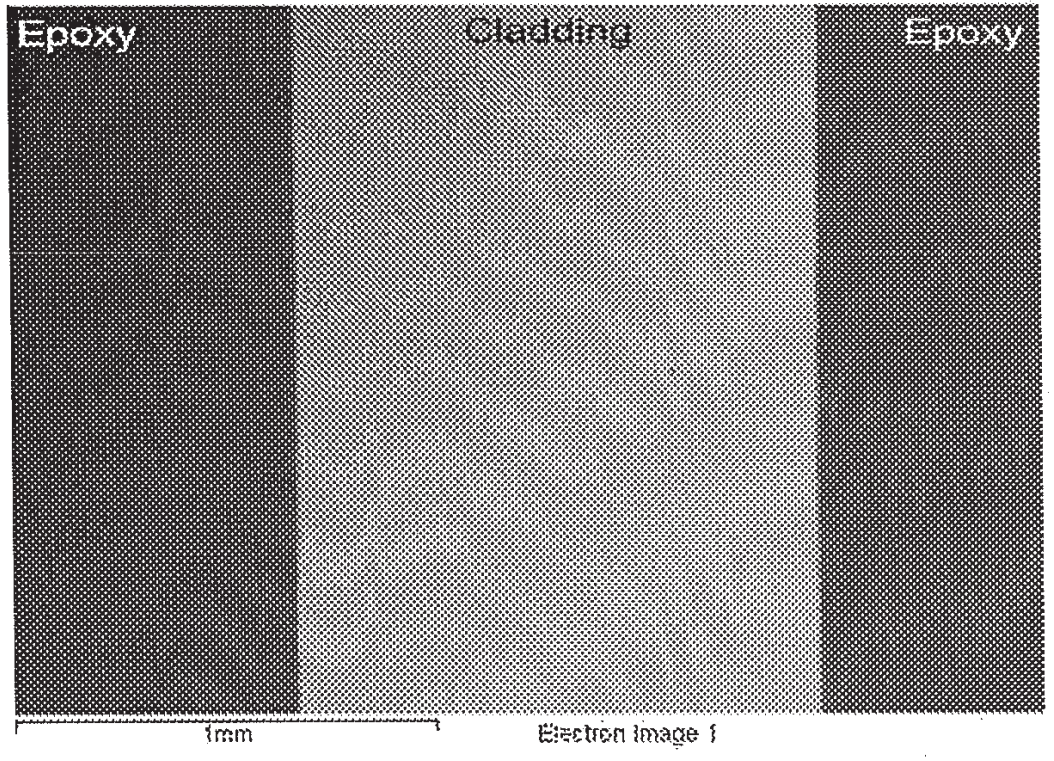

Figure 6: 50x-BSE - Low magnification SEM image of a fuel plate cross-section.



Figure 7: 1000x-BSE - SEM image of the cladding-to-epoxy interface. The oxide layer can be observed as the slightly darker area on the edge of the cladding. 


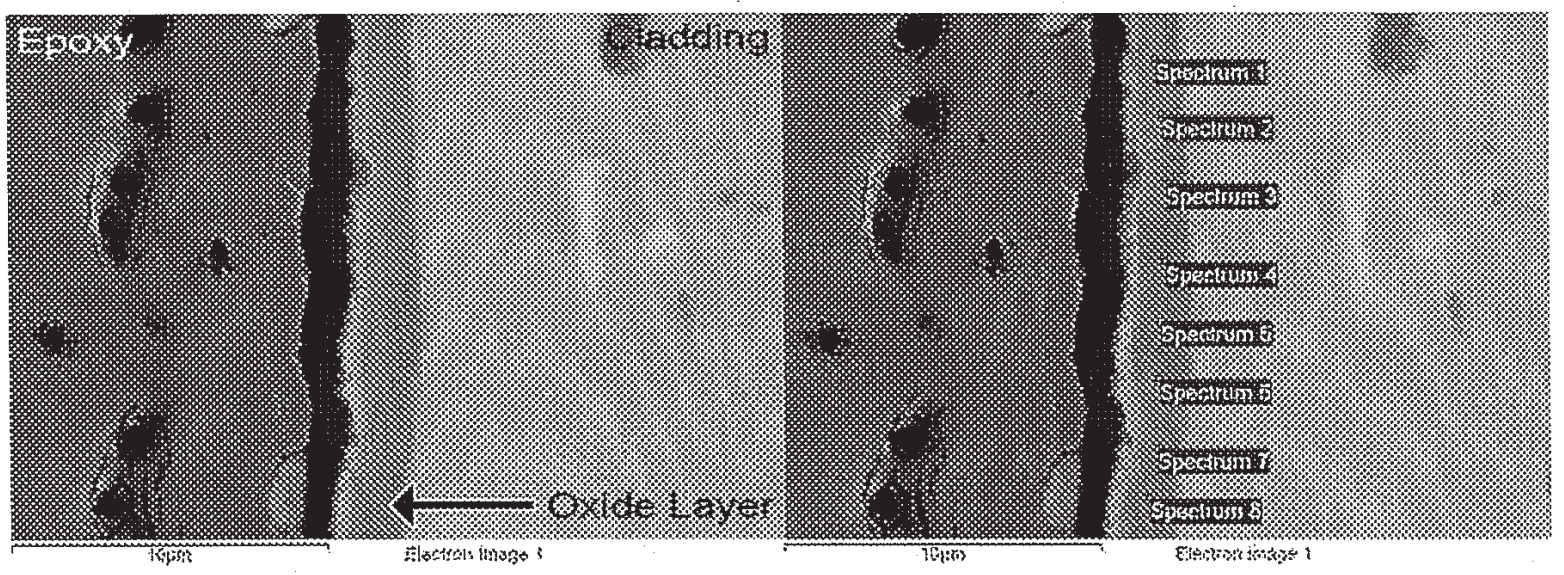

Processing option: All elements analyzed (normalized)

\begin{tabular}{|c|c|c|c|c|c|c|c|c|c|c|}
\hline Spectrum & In stats. & o & Mg & $\mathrm{Al}$ & Si & o & Mg & $\mathrm{Al}$ & $\mathrm{Si}$ & Total \\
\hline Spectrum 1 & YES & 55.63 & 0.53 & 42.63 & 1.21 & 42.65 & 0.62 & 55.11 & 1.63 & 100.00 \\
\hline Spectrum 2 & YES & 55.63 & 1.11 & 44.33 & 0.93 & 40.71 & 1.28 & 56.77 & 1.24 & 100.00 \\
\hline Spectrum 3 & YES & 50.07 & 0.42 & 48.73 & 0.78 & 37.30 & 0.48 & 61.21 & 1.02 & 100.00 \\
\hline Spectrum 4 & YES & 52.19 & 0.25 & 46.74 & 0.82 & 39.29 & 0.29 & 59.34 & 1.08 & 100.00 \\
\hline Spectrum 5 & $\overline{Y E S}$ & 58.13 & 0.33 & 40.58 & 0.96 & 45.15 & 0.39 & 53.16 & 1.31 & 100.00 \\
\hline Spectrum 6 & YES & 53.97 & 0.38 & 44.60 & 1.05 & 41.01 & 0.44 & 57.16 & 1.40 & 100.00 \\
\hline Spectrum 7 & YES & 54.82 & 0.25 & 44.43 & 0.50 & 41.84 & 0.29 & 57.20 & 0.67 & 100.00 \\
\hline Spectrum 8 & YES & 56.18 & 0.24 & 43.08 & 0.51 & 42.73 & 0.27 & 56.37 & 0.64 & 100.00 \\
\hline & Mean & 54.33 & 0.44 & 44.39 & 0.84 & 41.33 & 0.51 & 57.04 & 1.12 & 100.00 \\
\hline Std & Deviation & 2.48 & 0.29 & 2.50 & 0.25 & 2.37 & 0.33 & 2.45 & 0.34 & \\
\hline & Max. & 58.13 & 1.11 & 48.73 & 1.21 & 45.15 & 1.28 & 61.21 & 1.63 & \\
\hline & Min. & 50.07 & 0.24 & 40.58 & 0.50 & 37.30 & 0.27 & 53.16 & 0.64 & \\
\hline
\end{tabular}

Figure 8: 5000x-BSE - High magnification SEM image of the cladding-to-epoxy interface with elemental analysis of the oxide layer. 

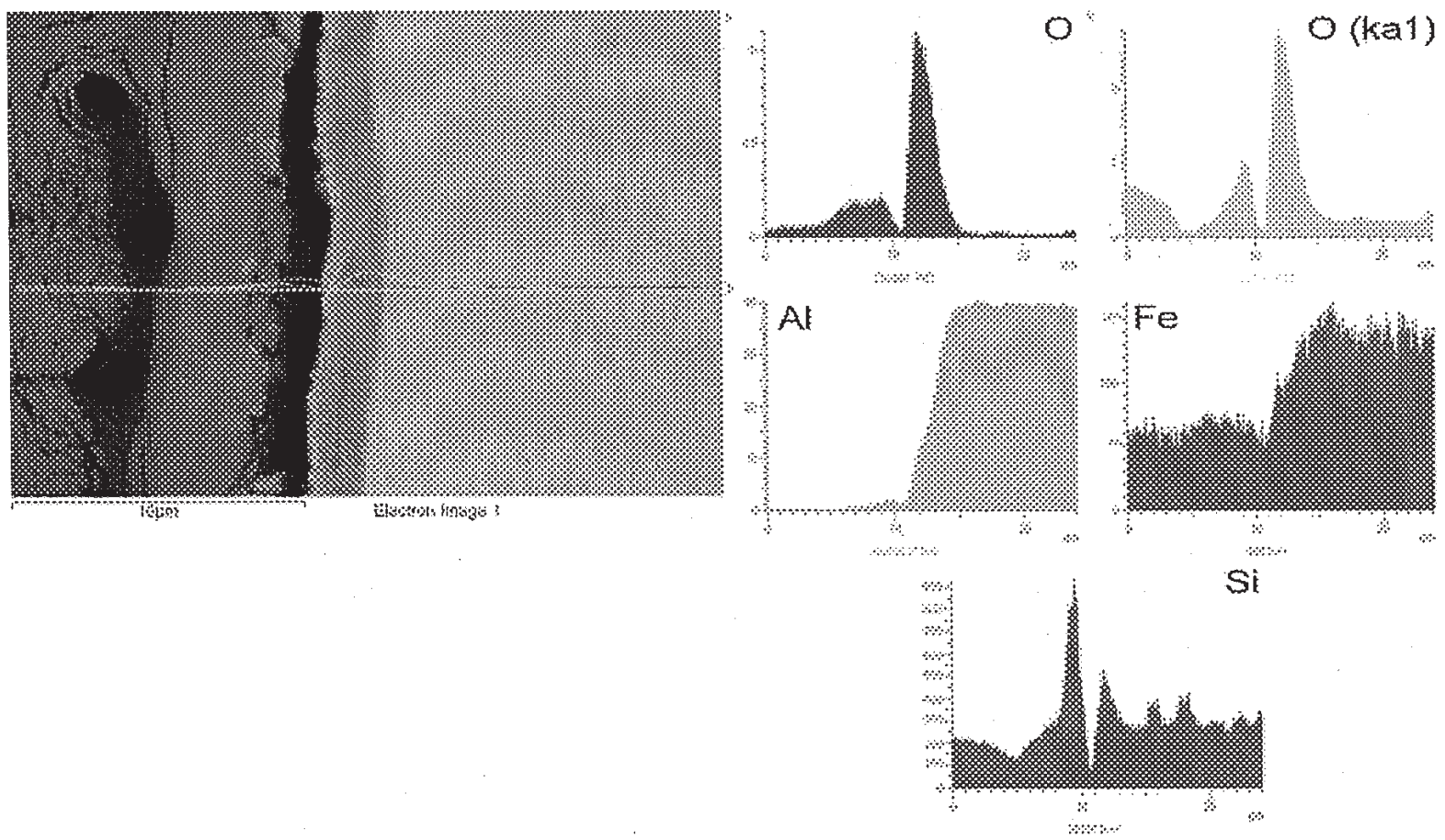

Si

Figure 9: 5000x-BSE - High magnification SEM image and linescan analysis of the oxide layer.

\subsection{Cladding-to-Cladding Interface Summary}

The cladding-to-cladding bonding of the AFIP-6 plates was acceptable and as expected for HIP bonded plates. Figure 10 shows a low magnification SEM image of a fuel plate. No bond line can be observed at this magnification. The defect at the end of the fuel zone will be addressed in section 4.6. Figure 11 is a higher magnification SEM image of the cladding just at the end of the fuel zone. The bond line can be observed in this image. Figure 12 is a SEM image with EDS/WDS of the cladding. The bond line can be observed, through the formation of second phase precipitates along the cladding-to-cladding interface. The second phase precipitates are enriched in magnesium, oxygen, and silicon.

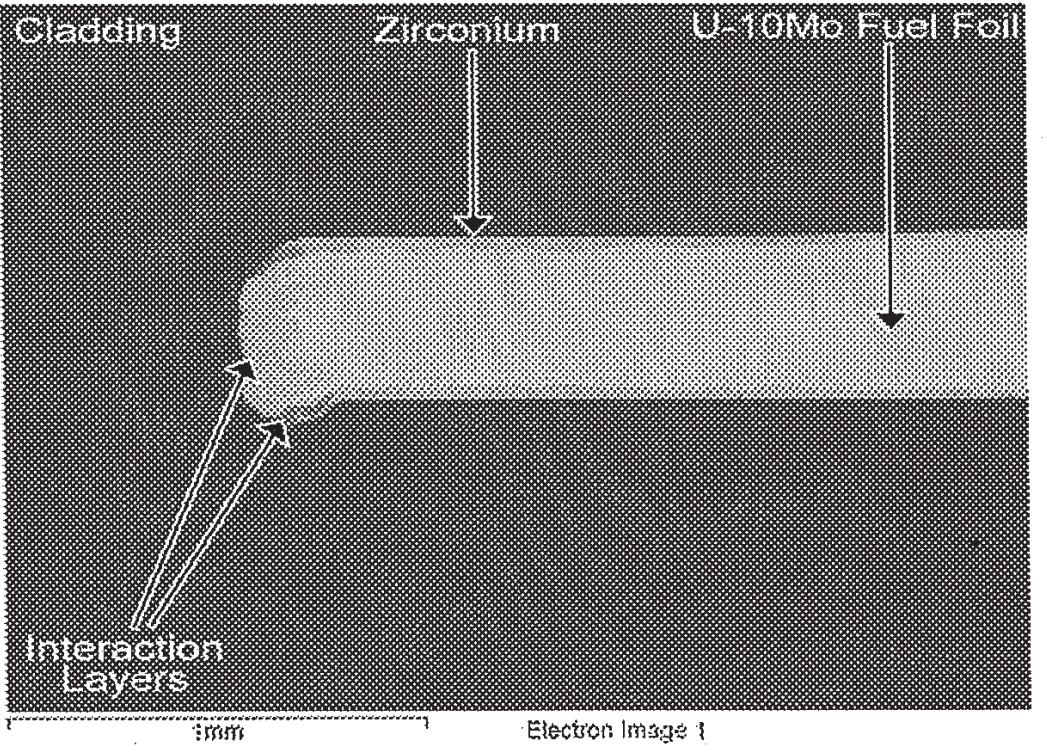

Figure 10: 346-1-F16, 50x-BSE - SEM image of the cladding-to-cladding area at the end of the fuel zone. No clear bond line can be seen. The shearing process causes the curved end. 


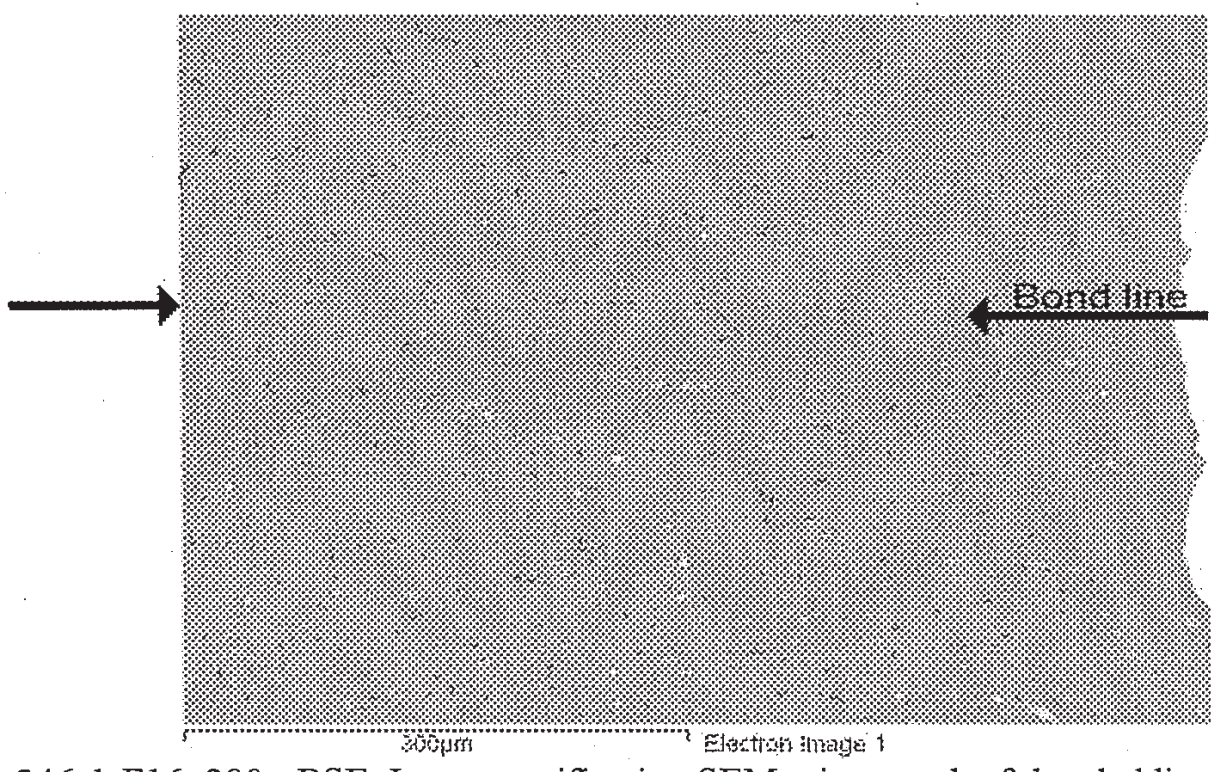

Figure 11: 346-1-F16, 200x-BSE: Low magnification SEM micrograph of the cladding-to-cladding bond line.
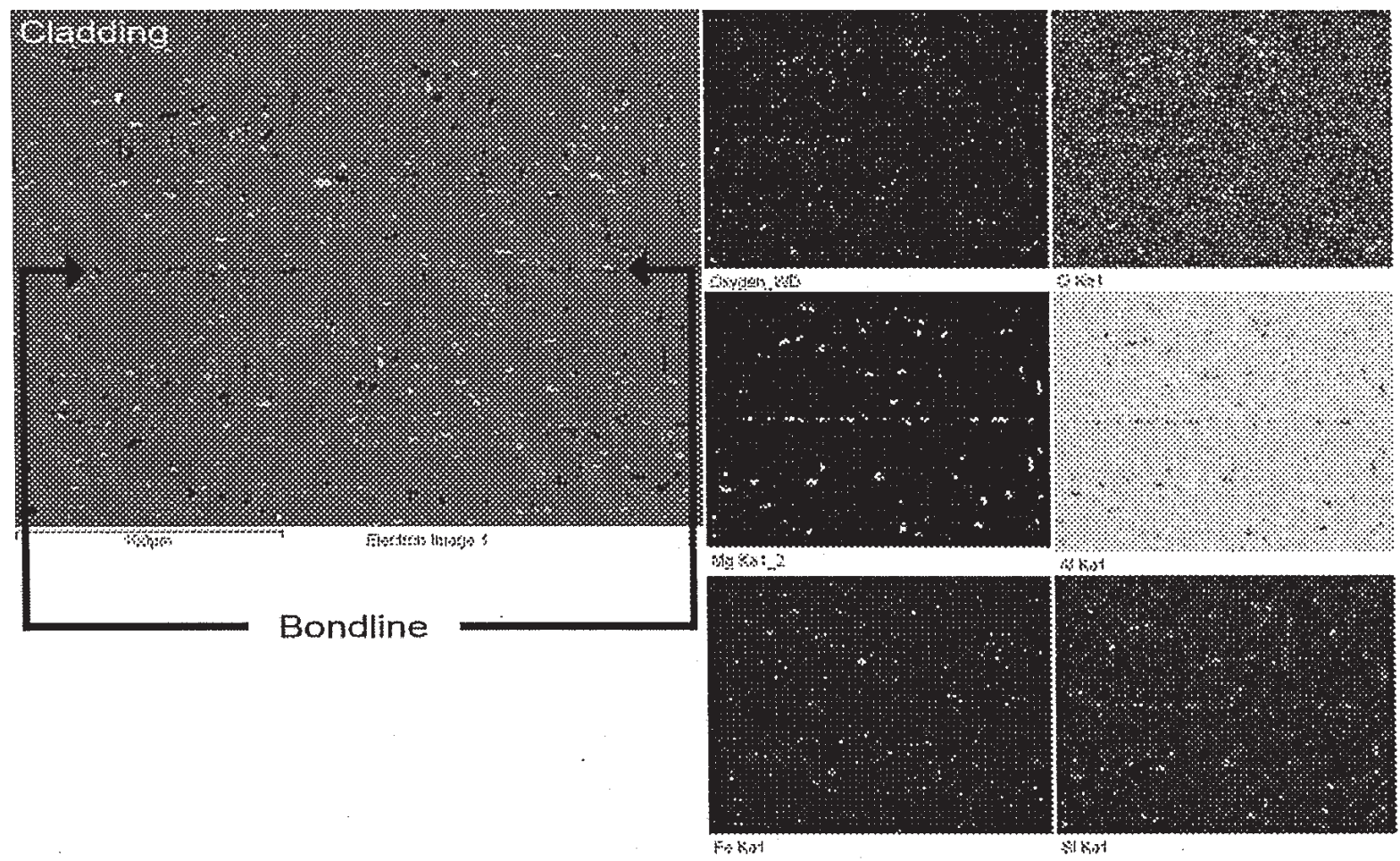

Bondline

Figure 12: JJ662, 500x-BSE - SEM micrograph with EDS/WDS of the cladding-to-cladding bond line. The absence of a solid line shows that good bonding occurred during the HIP process.

\subsection{Cladding-to-Zirconium Diffusion Barrier Interface Summary}

The cladding-to-diffusion barrier interface shows the formation of an interaction layer as shown in Figure 13: Figure 14 is a SEM image with EDS/WDS of the cladding-to-diffusion barrier interface. The interaction layer can be seen here as well as a silicon and magnesium rich particle that is highlighted by EDS. The interaction layer between the cladding and diffusion barrier comprised of a mixture of $(\mathrm{Al}, \mathrm{Si})_{3} \mathrm{Zr}$ and other phases. 


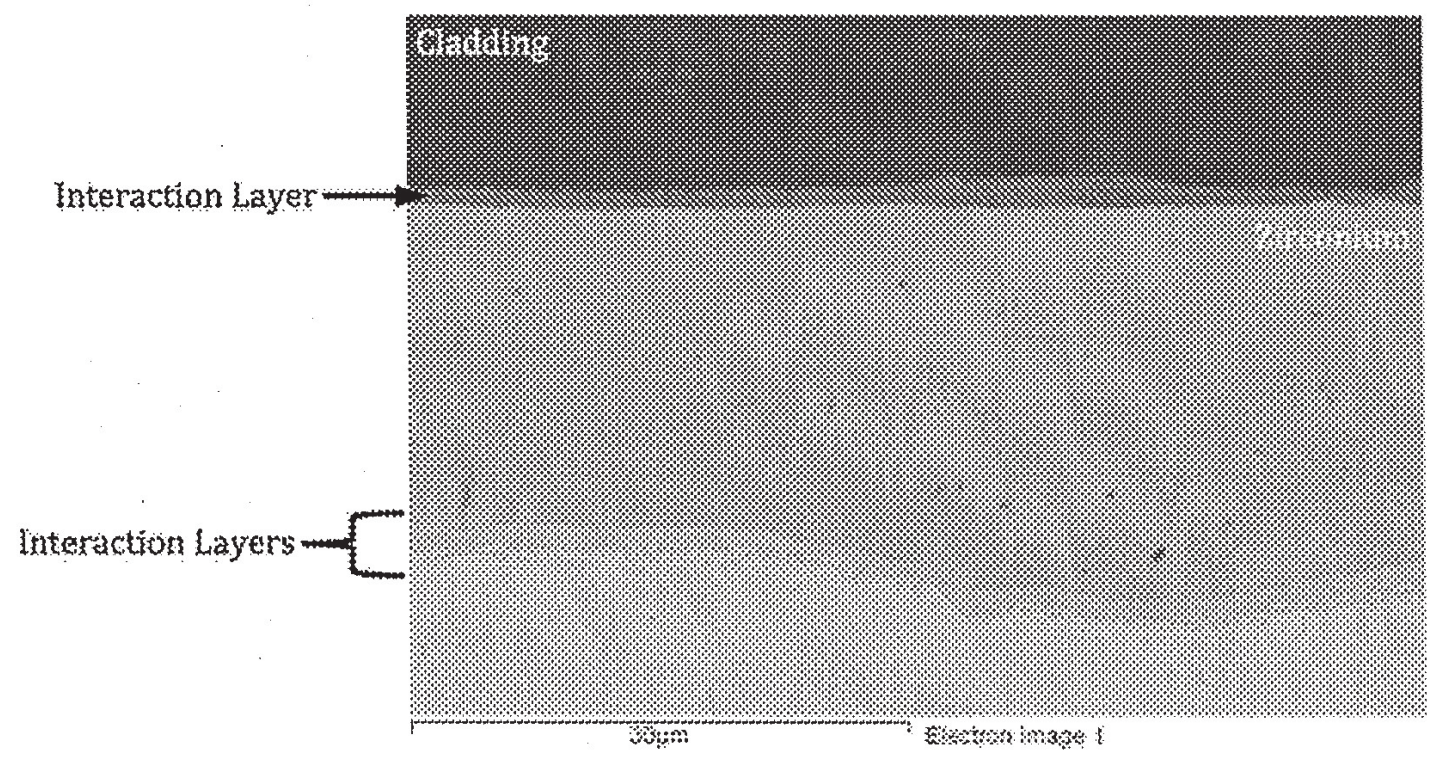

Figure 13: 346-1-F16, 2000x-BSE - High magnification SEM image of the cladding-to-diffusion barrier interface. An interaction layer can be observed between the two layers.
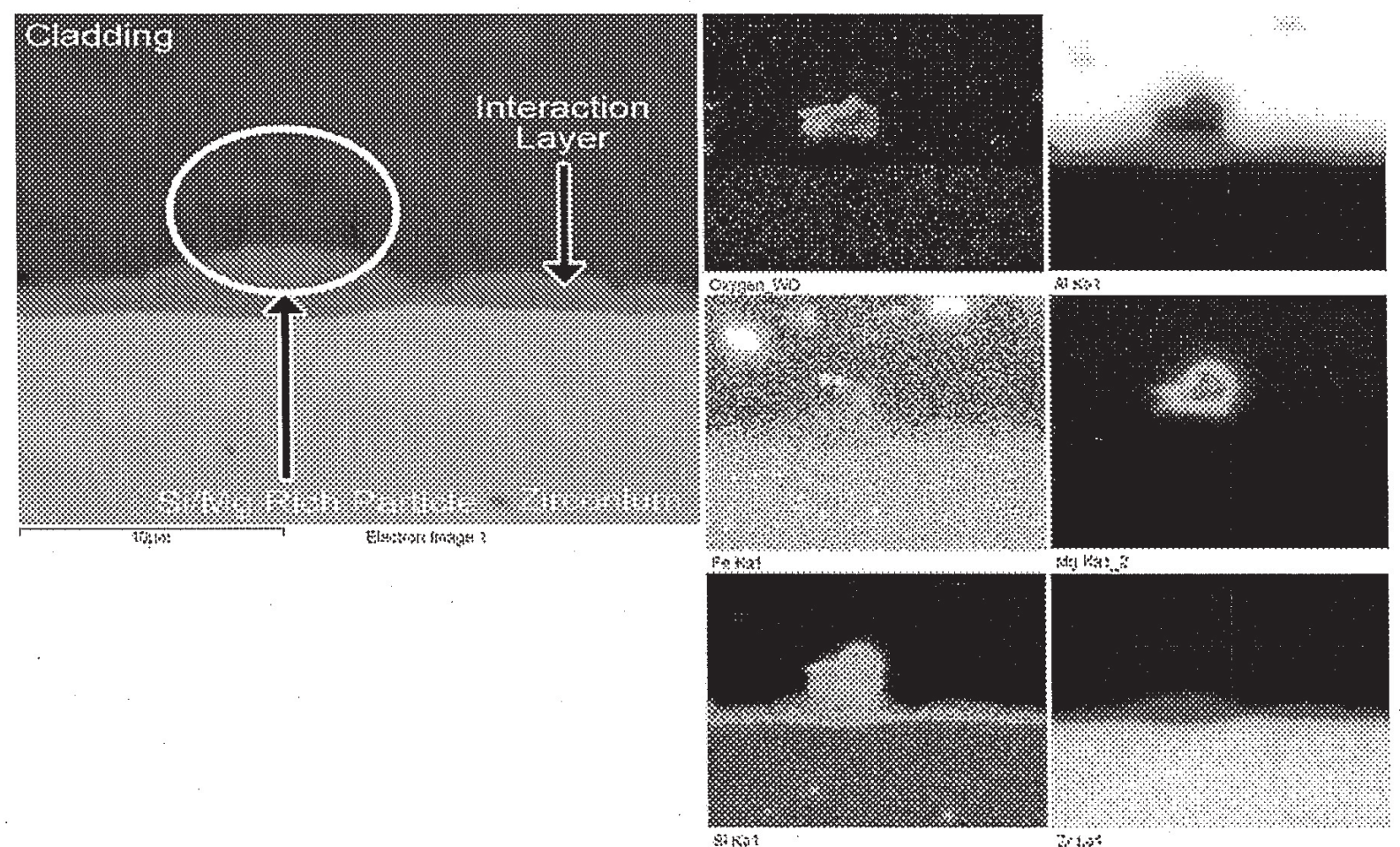

Figure 14: JJ662, 5000X-BSE - High magnification SEM image with EDS/WDS of the interaction layer between the cladding and diffusion barrier. Interaction layer is shown to be silicon rich. 


\subsection{Zirconium Diffusion Barrier-to-Fuel Foil Interface Summary}

The diffusion barrier-to-fuel foil interface shows the presence of multiple interaction layers. Figure 15 shows the formation of at least three interaction layers between the diffusion barrier and the fuel foil. The number to the left of the arrow corresponds to its layer. Using EDS/WDS in Figure 15 the layer composition was identified. Layer 1 is an oxygen rich area within the fuel foil. The WDS/EDS spectra show the presence of carbon, but this is an artifact due to both uranium and carbon sharing the same peak point in the spectra. This layer is also depleted of molybdenum. Layer 2 can be observed as the dark precipitate-like region. The layer is molybdenum rich as seen in the WDS/EDS images. $\mathrm{Mo}_{2} \mathrm{Zr}$ is the main phase in this layer. Layer 3 is the layer closest to the zirconium. This layer is comprised of $\mathrm{UZr}_{2}$, zirconium, and uranium. These layers are typical for HIP bonded plates and have been observed in previous experiments. Figure 16 is a high magnification SEM image with linescan analysis of the interfaces surrounding the zirconium diffusion barrier. The linescan data confirms the observations in Figure 15.

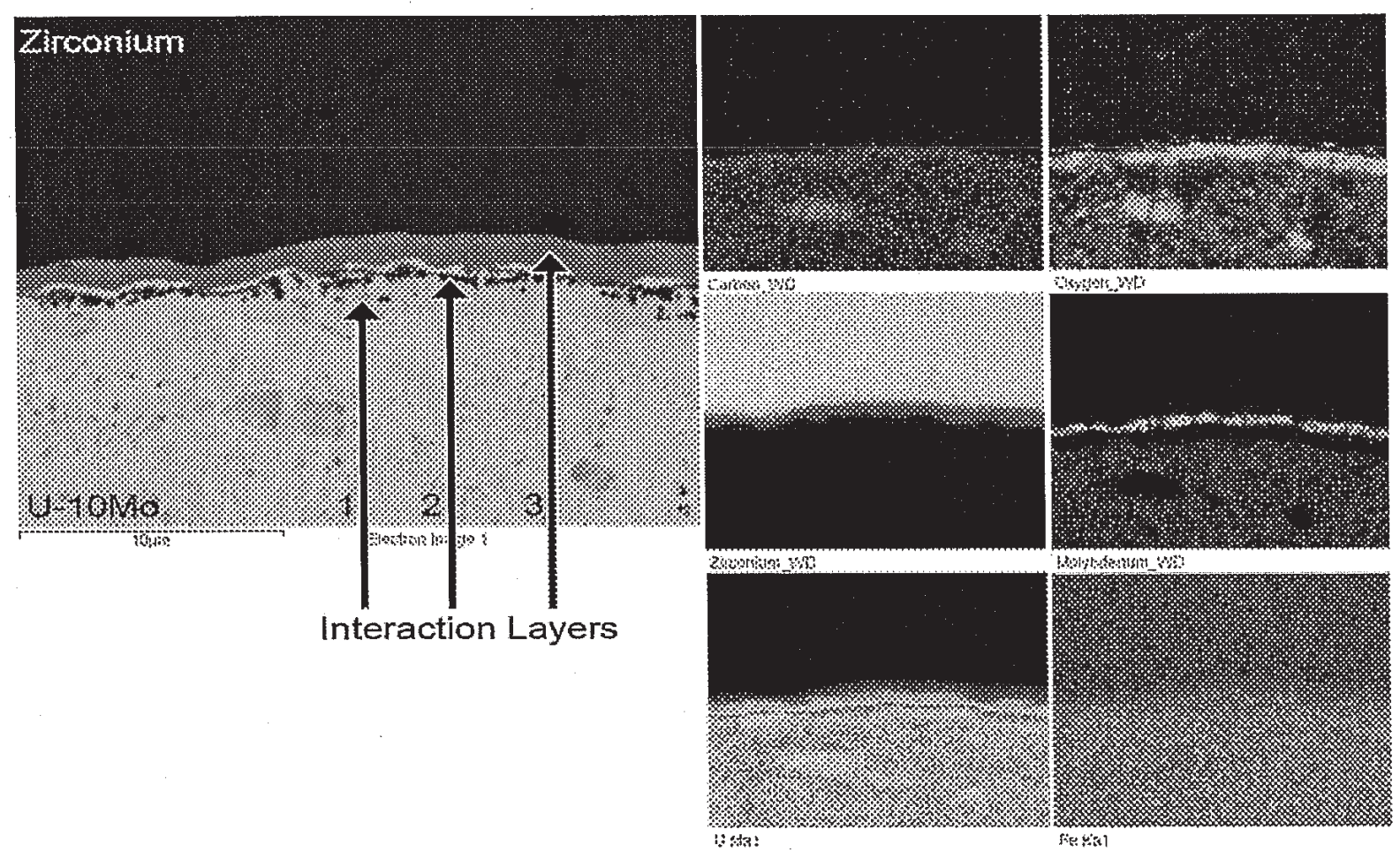

Figure 15: JJ662, 5000x-BSE - High magnification SEM image with EDS/WDS of the interaction layers between the zirconium diffusion barrier and fuel foil. 

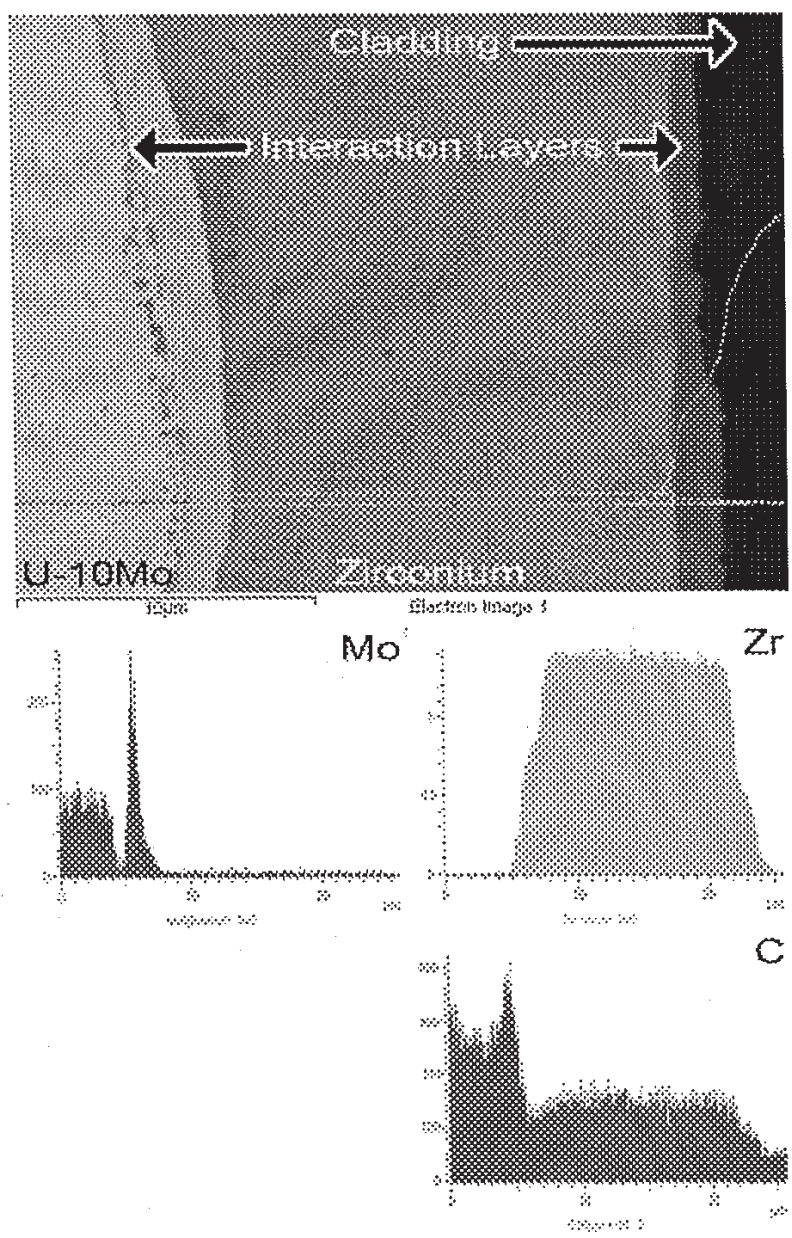
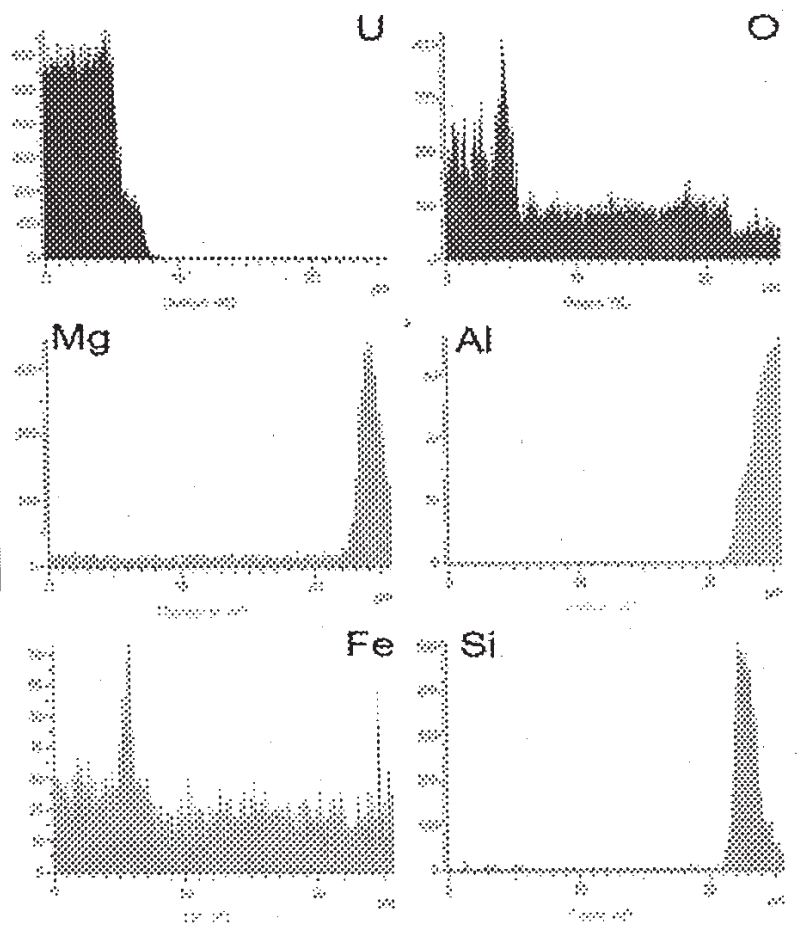

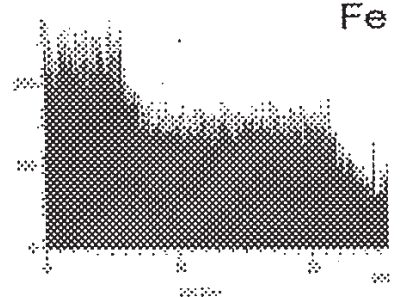

Fe

Figure 16: JJ662, 5000x-BSE - High magnification SEM image with linescan analysis of the diffusion barrier interfaces.

\subsection{U-10Mo Fuel Foil Summary}

The U-10Mo fuel foil exhibits relatively uniform thickness with some variation as shown in Figure 17. The fuel foil shows at least two specific features, the existence of carbides and oxides and decomposition. Table 4 shows that the concentration of carbon in the fuel foil is higher than that of other representative AFIP fuels. This increased concentration of carbon could be responsible for the more pronounced carbides observed in the fuel foil. Figure 18 is a higher magnification SEM image of the fuel foil. The indicated dark precipitates are carbides and oxides that have formed within the fuel foil. The larger, less pronounced dark area is decomposition of the fuel. Figure 19 is a high magnification SEM image with EDS/WDS of a region of the fuel foil where the fuel decomposition is more obvious. EDS/WDS shows the dark regions to be molybdenum deficient areas within the fuel. Figure 20 is a SEM image with WDS/EDS of a defect within the U-10Mo fuel foil. As shown by EDS/WDS the defect is comprised of mainly of zirconium indicating a displacement of zirconium into the fuel foil that likely occurred during the fuel fabrication process.

Table 4: Carbon Concentration of Representative U-Mo AFIP Fuel Fabricated at Y-12

\begin{tabular}{|l|c|c|c|}
\hline & AFIP-3 & AFIP-4 & AFIP-6 \\
\hline Carbon $(\mu \mathrm{g} / \mathrm{gU})$ & 411 & 425 & 693 \\
\hline
\end{tabular}




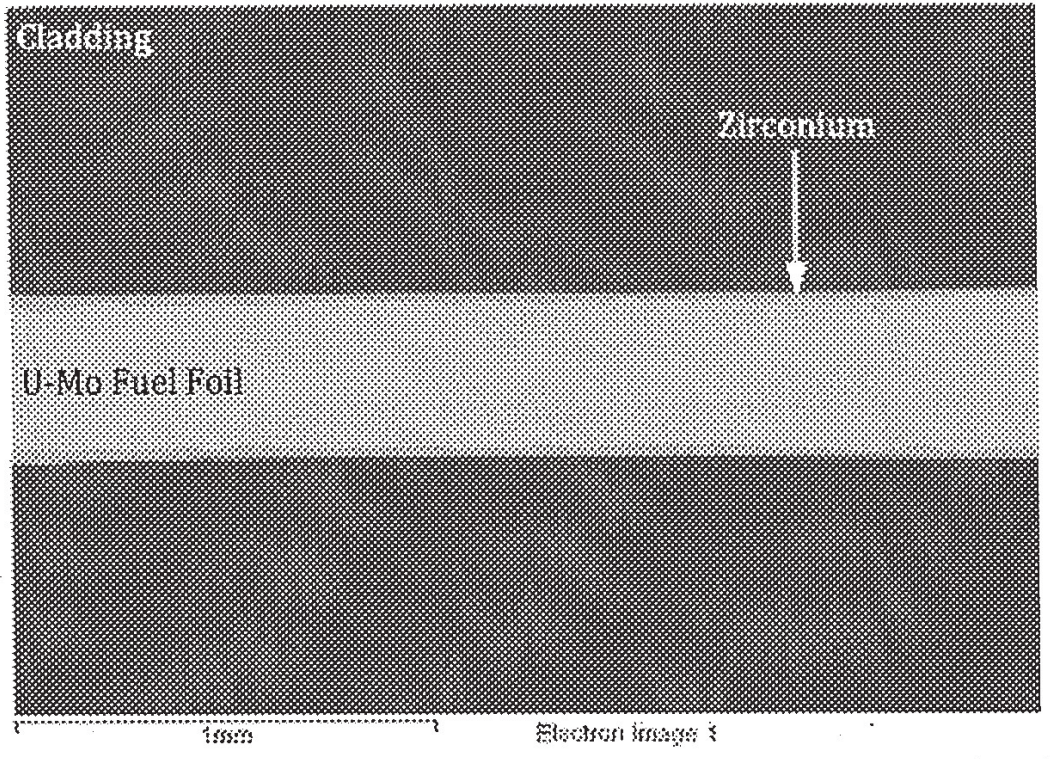

Figure 17: 346-1-F16, 50x-BSE - Low magnification SEM micrograph showing the cross-section of the fuel plate.

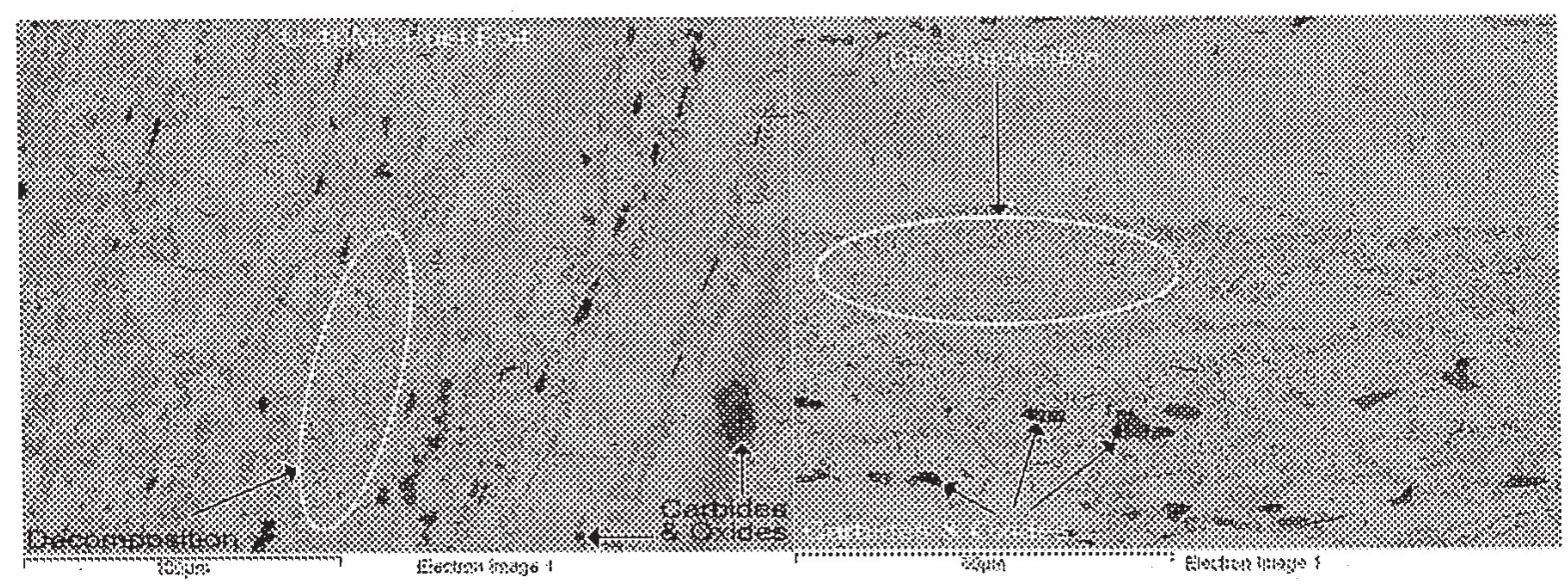

Figure 18: SEM image of the U-10 fuel foil. The large dark defects are carbides and oxides within the fuel. The larger, darker areas are fuel decomposition. 

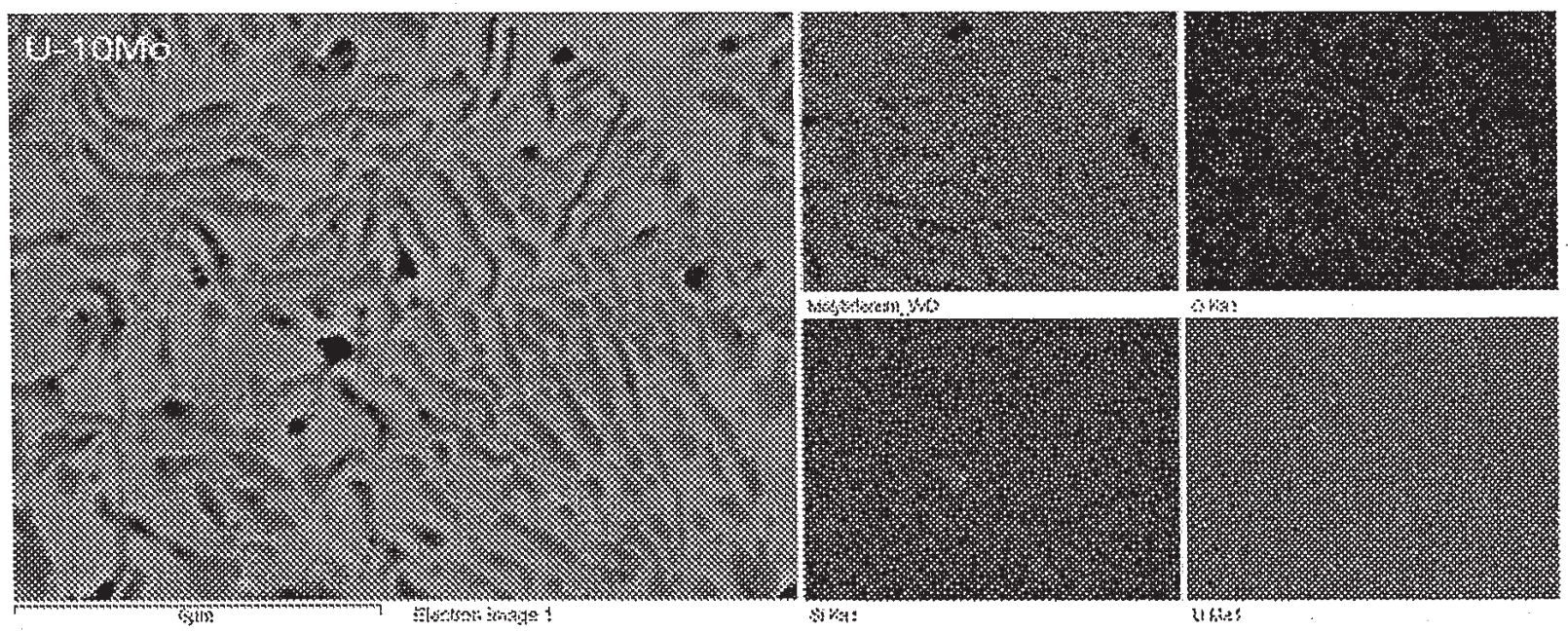

Figure 19: High magnification SEM image of the U-10Mo fuel foil. The dark region indicated in the fuel is decomposition.

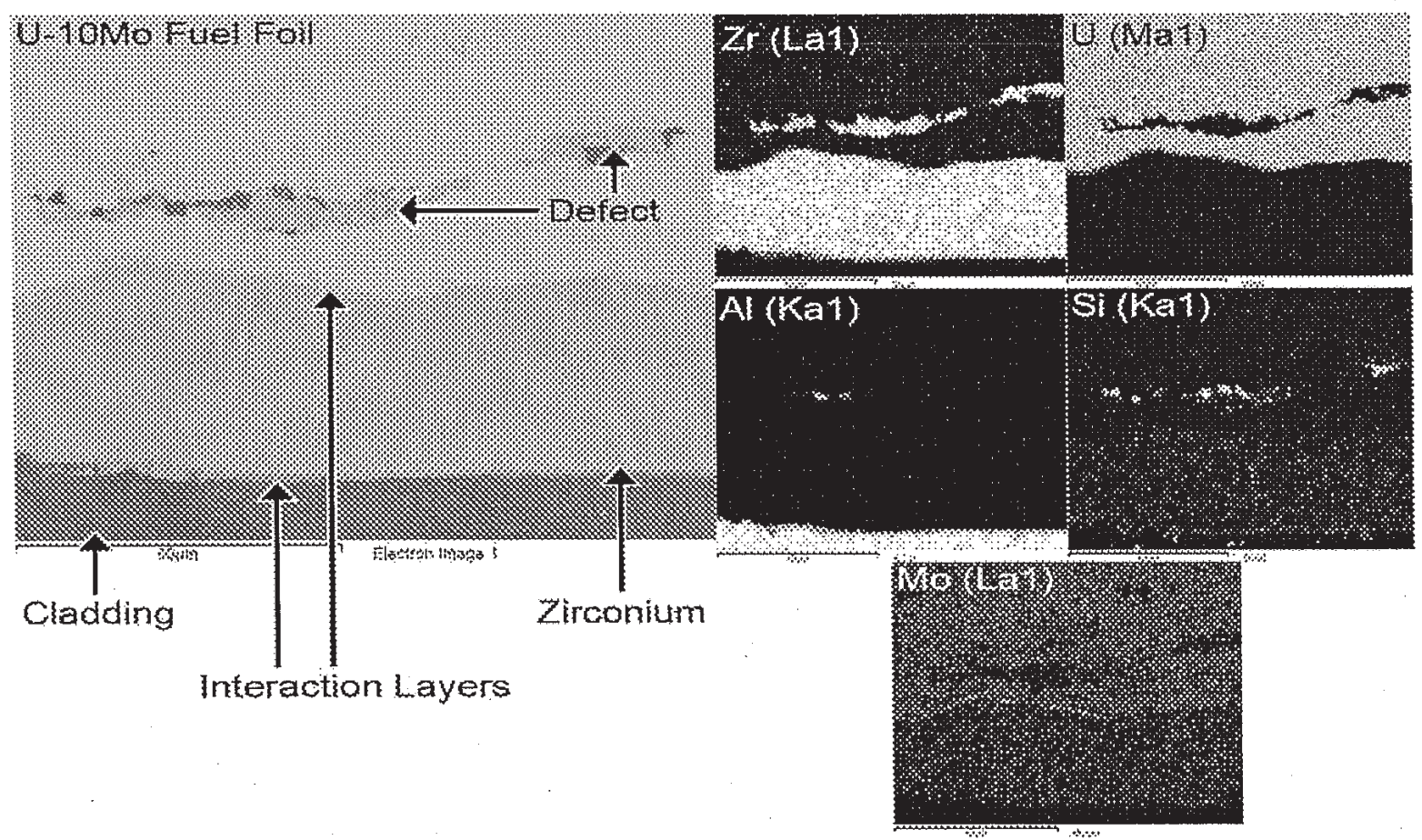

Figure 20: BM814-F10, 1000x-BSE - SEM image with EDS/WDS of a defect within the U$10 \mathrm{Mo}$ fuel foil. Shown in a displacement of the zirconium diffusion barrier within the fuel foil. 


\subsection{Fuel Zone Edge Summary}

The edge of the fuel zone shows a high degree of distortion compared to that seen in previous experiments that have been HIP bonded. The distortion of the ends can be attributed to the foil shearing process, which distorted the shape of the fuel ends as well as creating ragged edges. The combination of plastic deformation and a greater surface area for cladding-to-fuel interaction to take place resulted in large areas of interaction.

Figure 21 and Figure 22 are low magnification SEM images of the fuel zone ends. Both ends show distortion in the form of bending and ragged edges. Both ends show the formation of a large interaction layer. Figure 22 also has a defect in the form of cracking; this is due to the sample preparation process. Figure 23 is an SEM image with EDS/WDS of the interaction layers that have formed at the end of the fuel foil. The cladding has significantly interacted with both the fuel foil and zirconium to form at least two interaction layers at the end of the fuel foil. Some cracking can also be observed in one of the interaction layers. Figure 24 is an SEM image with EDS/WDS element mapping. Element mapping shows that the two interaction layers are created through the interaction of the U-Mo fuel foil and cladding and the cladding and the zirconium diffusion barrier. EDS/WDS analysis shows the presence of silicon in the zirconium diffusion barrier. This is an artifact due to zirconium and silicon has signal peaks in very close proximity. Figure 25 is an SEM image with elemental analysis of the end of the fuel zone. Elemental analysis confirms the $\mathrm{Zr} / \mathrm{Al}-6061$ and $\mathrm{U}-\mathrm{Mo} / \mathrm{Al}-6061$ interaction layer formation.

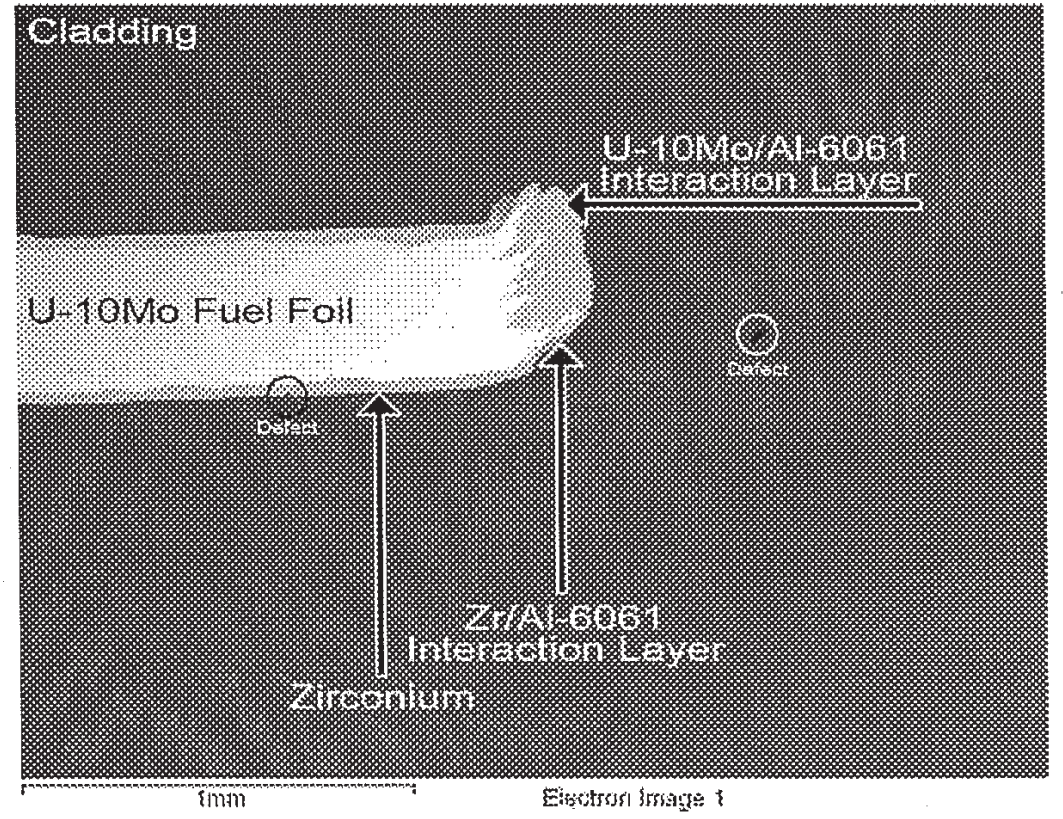

Figure 21: JJ663-F16, 50x-BSE - Low magnification SEM image of the end of the fuel zone. The distortion of the end and high degree of interaction is due to the shearing of the fuel foil. 


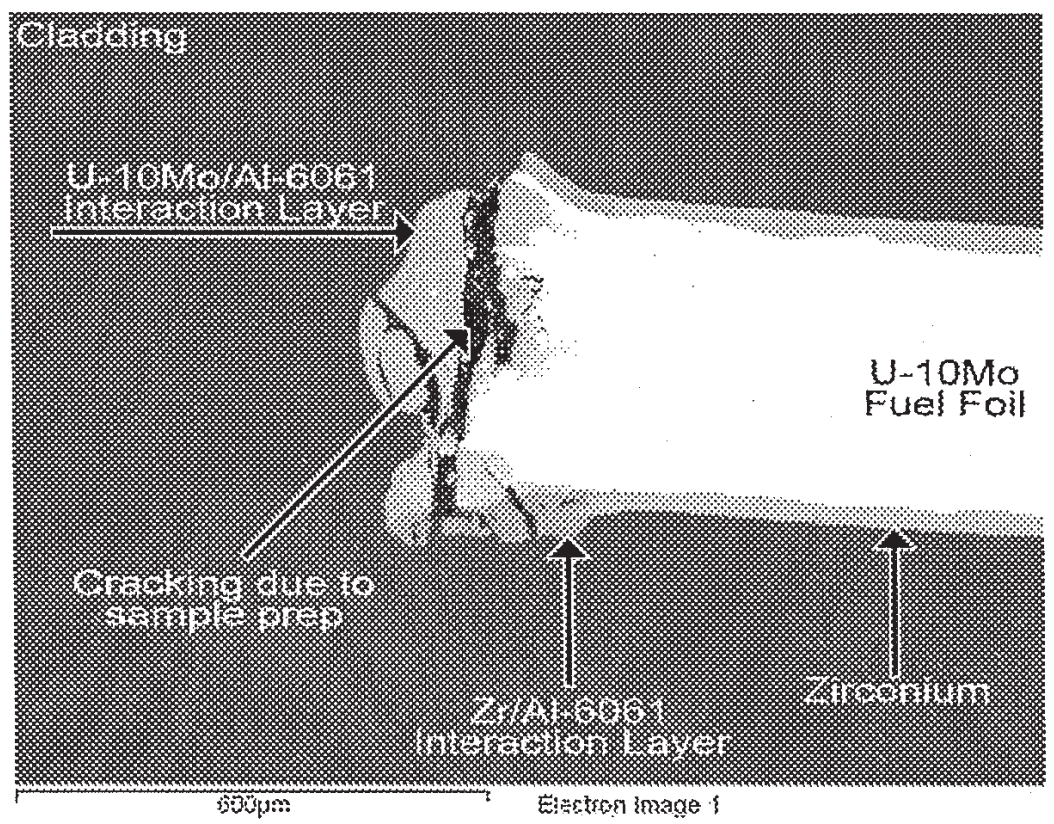

Figure 22: BM811-F12, 100x-BSE - Low magnification SEM image of the end of the fuel zone. The high level of interaction and distortion of the end can be contributed to the shearing process.

The cracking occurred during sample preparation process.
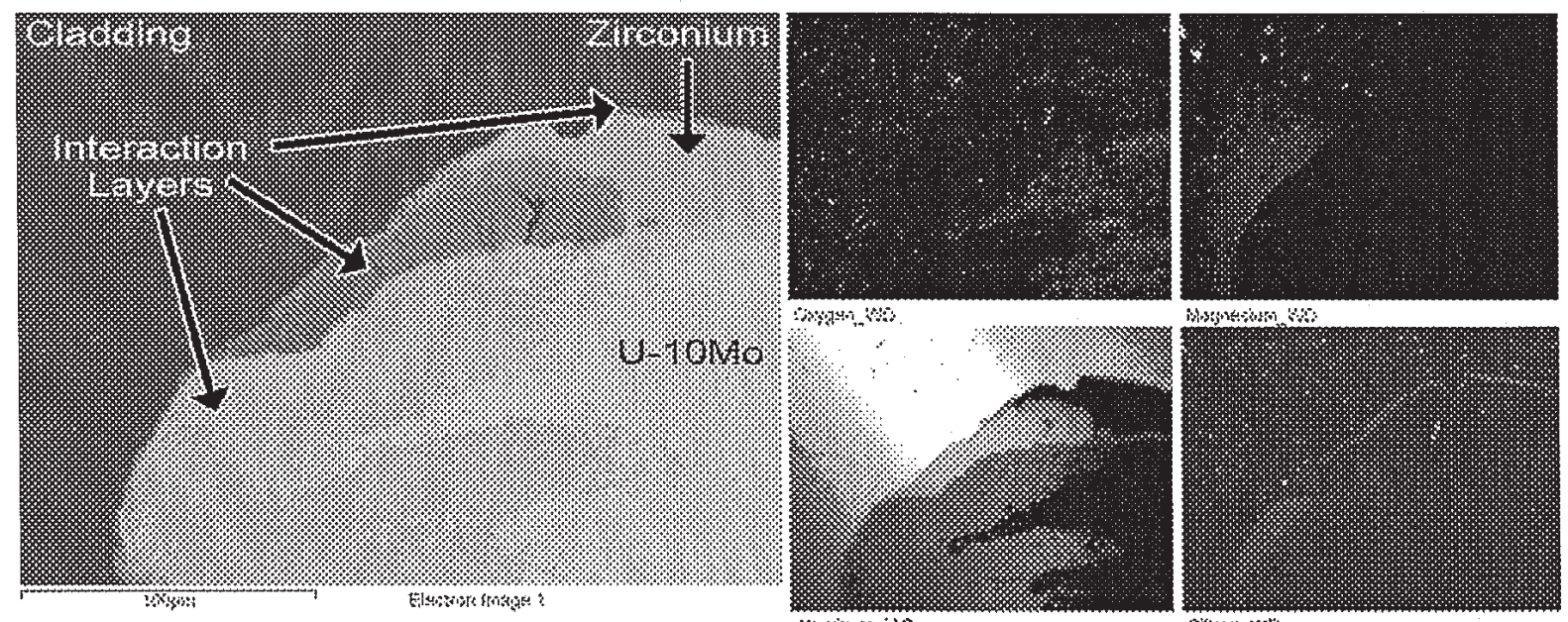

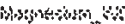
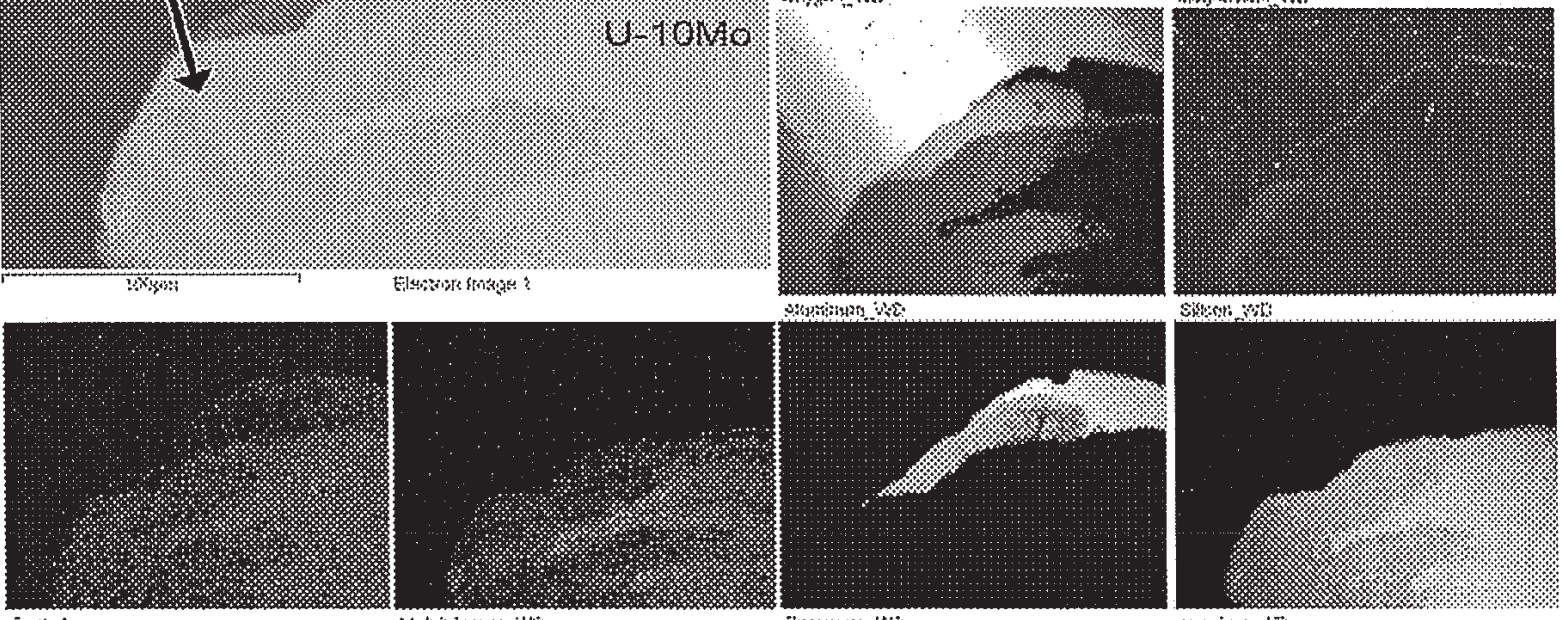

5 sit

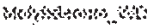

Zasomiston

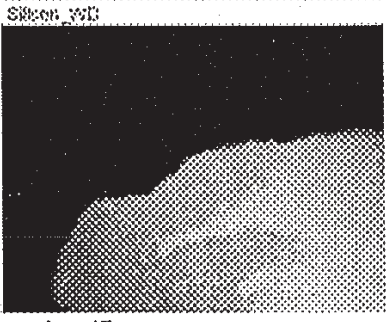

Figure 23: JJ662, 500x-BSE - SEM image with EDS/WDS of the cladding-to-zirconium and cladding-to- fuel foil interaction layers. Cracking can be seen within the interaction layer. 


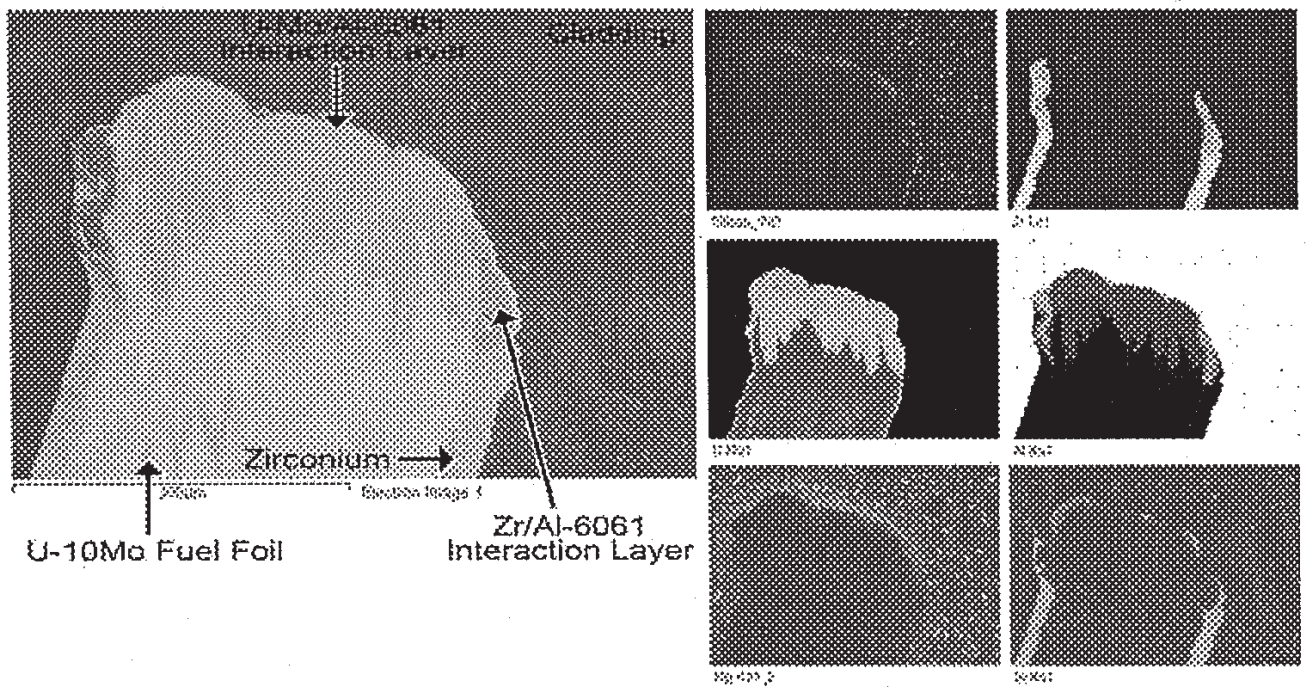

Figure 24: 346-1-F-16, 200x-BSE - SEM image and element mapping of the fuel foil end. Two interaction layers can be observed, a combination of $\mathrm{Zr} / \mathrm{Al}-6061$ and U-Mo/Al-6061.

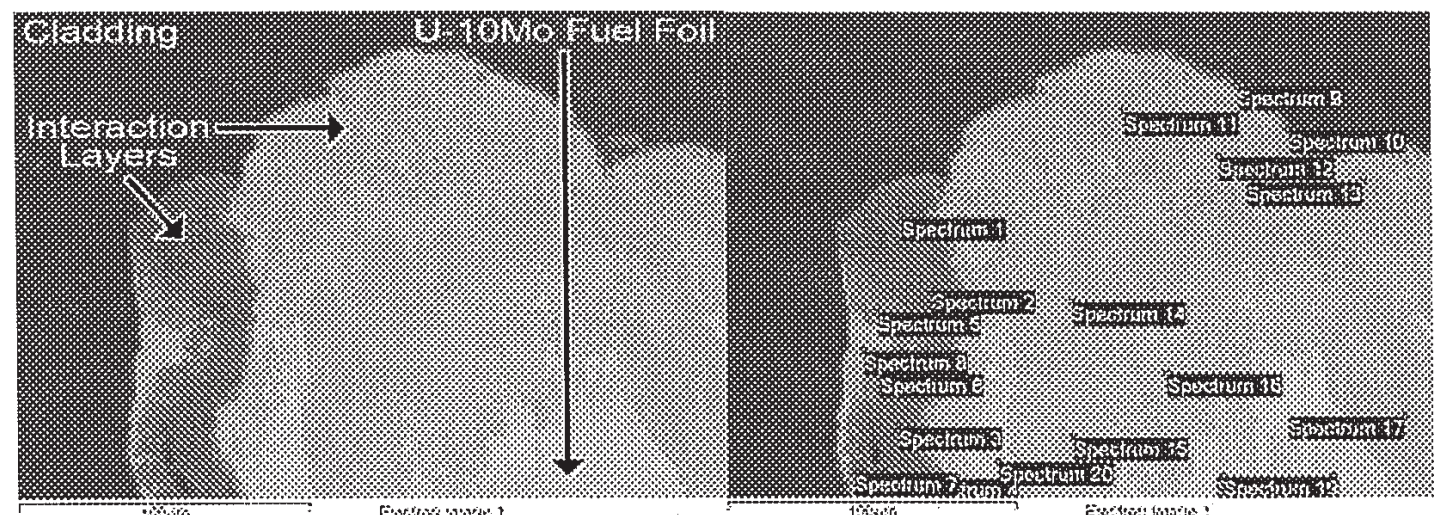

Processing option: All elements analyzed (normalized)

Processing option: All elements analyzed (normalized)

\begin{tabular}{|c|c|c|c|c|c|c|c|c|}
\hline Spectrun & In Stats & $\mathrm{Mg}$ & $\mathrm{Al}$ & $\mathrm{Si}$ & $\mathrm{Zr}$ & Mo & $\mathrm{U}$ & Total \\
\hline 1 & Yes & -0.37 & 42.06 & 1.02 & 56.06 & 0.74 & 0.49 & 100.00 \\
\hline 2 & Yes & -0.51 & 44.02 & 0.86 & 54.36 & 0.82 & 0.45 & 100.00 \\
\hline 3 & Yes & -0.55 & 41.77 & 0.73 & 57.32 & 0.75 & -0.01 & 100.00 \\
\hline 4 & Yes & -0.55 & 41.64 & 0.86 & 57.24 & 0.75 & 0.07 & 100.00 \\
\hline 5 & Yes & -0.45 & 31.33 & 0.76 & 66.28 & 1.81 & 0.27 & 100.00 \\
\hline 6 & Yes & -0.43 & 32.22 & 0.67 & 64.89 & 1.64 & 0.02 & 100.00 \\
\hline 7 & Yes & -0.51 & 31.35 & 0.79 & 66.87 & 1.46 & 0.04 & 100.00 \\
\hline 8 & Yes & -0.03 & 0.11 & 0.58 & 94.74 & 4.71 & -0.11 & 100.00 \\
\hline 9 & Yes & 1.51 & 72.22 & 0.44 & 2.12 & .4 .30 & 28.01 & 100.00 \\
\hline 10 & Yes & 0.55 & 68.06 & 0.49 & 2.25 & -3.93 & 32.57 & 100.00 \\
\hline 11 & Yes & -0.19 & 41.48 & 1.22 & 1.12 & 1.89 & 54.48 & 100.00 \\
\hline 12 & Yes & -0.18 & 40.50 & 1.25 & 0.96 & 2.21 & 55.26 & 100.00 \\
\hline 13 & Yes & -0.04 & 41.79 & 1.65 & 0.86 & 3.76 & 51.99 & 100.00 \\
\hline 14 & Yes & -0.34 & 35.09 & 0.34 & 0.88 & 2.64 & 61.39 & 100.00 \\
\hline 15 & Yes & -0.50 & 33.47 & 0.21 & 0.84 & 2.46 & 63.52 & 100.00 \\
\hline 16 & Yes & -0.57 & 34.49 & 0.20 & 0.69 & 3.36 & 61.83 & 100.00 \\
\hline 17 & Yes & -0.45 & 34.73 & 0.35 & 0.41 & 3.20 & 61.76 & 100.00 \\
\hline 18 & Yes & -0.12 & 0.33 & -0.05 & 0.35 & 9.14 & 90.36 & 100.00 \\
\hline 19 & Yes & -0.02 & 0.21 & -0.10 & 0.37 & 8.29 & 91.20 & 100.00 \\
\hline 20 & Yes & 0.01 & 0.35 & 1.15 & 0.27 & 9.21 & 89.02 & 100.00 \\
\hline \multicolumn{2}{|c|}{ Mean } & -0.19 & 33.41 & 0.67 & 26.44 & 2.53 & 37.13 & 100.00 \\
\hline \multicolumn{2}{|c|}{ Std. Dev. } & 0.49 & 20.04 & 0.45 & 33,04 & 3.50 & 34.68 & \\
\hline \multicolumn{2}{|c|}{ Max. } & 1.51 & 72.22 & 1.65 & 94.74 & 9.21 & 91.20 & \\
\hline \multicolumn{2}{|c|}{ Min. } & -0.57 & 0.11 & -0.10 & 0.27 & -4.30 & -0.11 & \\
\hline
\end{tabular}

\begin{tabular}{cccccc}
$\mathrm{Mg}$ & $\mathrm{Al}$ & $\mathrm{Si}$ & $\mathrm{Zr}$ & $\mathrm{Mo}$ & $\mathrm{U}$ \\
\hline-0.68 & 70.72 & 1.65 & 27.88 & 0.35 & 0.09 \\
\hline-0.93 & 72.59 & 1.35 & 26.52 & 0.38 & 0.08 \\
\hline-1.03 & 70.77 & 1.18 & 28.73 & 0.36 & 0.00 \\
\hline-1.04 & 70.58 & 1.40 & 28.70 & 0.36 & 0.01 \\
\hline-0.97 & 60.59 & 1.41 & 37.92 & 0.99 & 0.06 \\
\hline-0.91 & 62.63 & 1.21 & 36.19 & 0.87 & 0.00 \\
\hline-1.10 & 60.59 & 1.47 & 38.23 & 0.79 & 0.01 \\
\hline-0.10 & 0.37 & 1.85 & 93.50 & 4.42 & -0.04 \\
\hline 2.18 & 93.90 & 0.55 & 0.82 & -1.57 & 4.13 \\
\hline 0.85 & 94.00 & 0.66 & 0.92 & -1.53 & 5.10 \\
\hline-0.44 & 83.84 & 2.37 & 0.67 & 1.08 & 12.48 \\
\hline-0.41 & 83.22 & 2.47 & 0.58 & 1.28 & 12.87 \\
\hline-0.09 & 82.71 & 3.13 & 0.51 & 2.09 & 11.66 \\
\hline-0.87 & 81.60 & 0.76 & 0.60 & 1.72 & 16.18 \\
\hline-1.36 & 81.13 & 0.50 & 0.60 & 1.68 & 17.46 \\
\hline-1.51 & 81.72 & 0.46 & 0.49 & 2.24 & 16.61 \\
\hline-1.17 & 81.54 & 0.78 & 0.29 & 2.11 & 16.44 \\
\hline-0.99 & 2.49 & -0.35 & 0.78 & 19.67 & 78.40 \\
\hline 0.14 & 1.65 & -0.71 & 0.85 & 18.05 & 80.01 \\
\hline 0.05 & 2.44 & 7.77 & 0.56 & 18.21 & 70.97 \\
\hline-0.52 & 61.95 & 1.50 & 16.27 & 3.68 & 17.13 \\
\hline 0.86 & 32.27 & 1.73 & 23.83 & 6.58 & 26.49 \\
\hline 2.18 & 94.00 & 7.77 & 93.50 & 19.67 & 80.01 \\
\hline & 0.37 & -0.71 & 0.29 & -1.57 & -0.04 \\
\hline-111 & 1.6109 & & &
\end{tabular}

Figure 25: 346-1-F16, 500x-BSE - SEM image and EDS analysis of the interaction layers at the end of the fuel foil. 


\subsection{Other Significant Features}

Figure 26 is an SEM image of a defect present in the zirconium diffusion barrier. The defect appears to be a gap caused during foil shearing. This type of defect has been seen in previous foil samples taken after the foil rolling process. Figure 27 is a higher magnification SEM image of the defect in the diffusion barrier. The backscatter electron (BSE) image (left) and secondary electron (SE) image (right) both show the formation of interaction layers on the top edge of the gap. The presence of these interaction layers confirms that the defect was created after the foil rolling process that created the interaction layers between the fuel foil and diffusion barrier. A portion of the zirconium diffusion barrier was removed during the sample preparation process creating the gap. Figure 28 is an SEM image of a crack/delamination between the cladding and zirconium diffusion barrier. It is not readily apparent based on the figure whether the crack/delamination occurred during the sample preparation process.

All of the aforementioned defects were not caused as a result of manufacturing issues. The defects were either caused during the shearing phase of foil preparation or the sample preparation phases. These defects are due to the brittle nature of the interaction phases created during the rolling and HIP bonding processes.

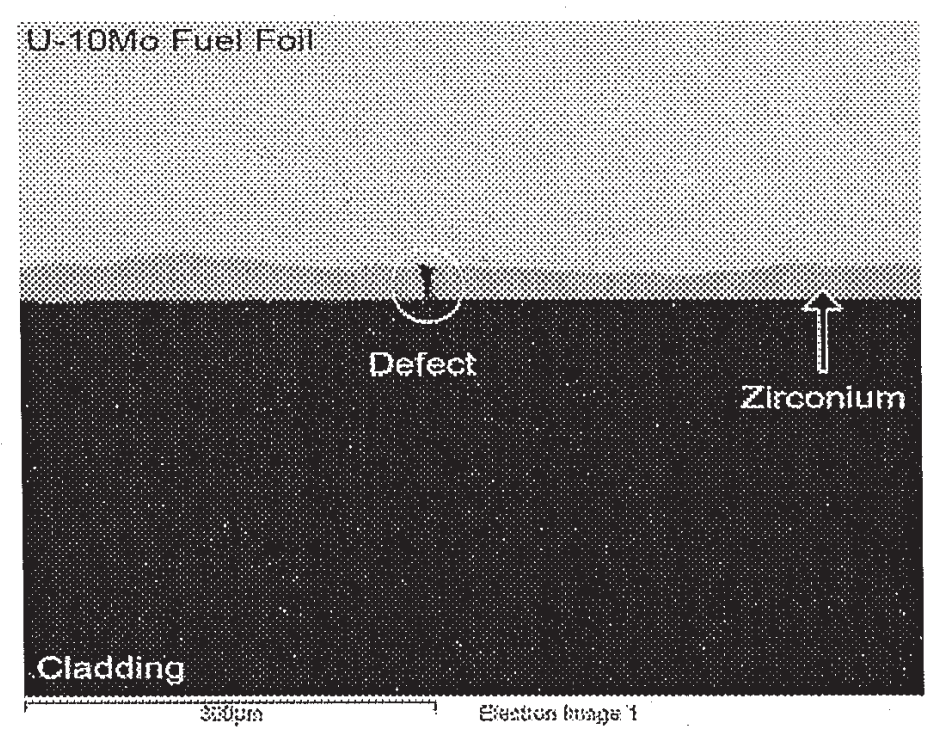

Figure 26: JJ663-F11, 200x-BSE - Low magnification SEM image highlighting the indicated defect in the diffusion barrier. The defect appears to be a gap in the diffusion barrier. 


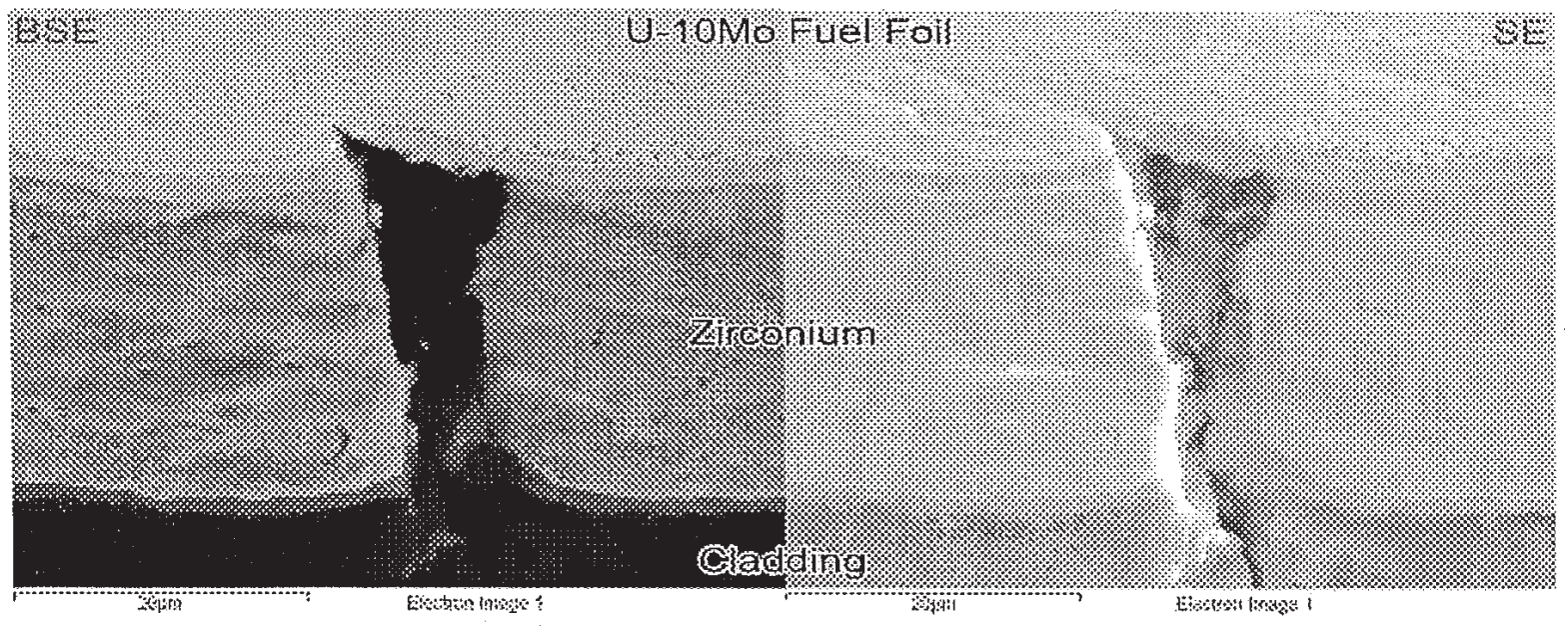

Figure 27: JJ663-F11, 2500x-BSE/SE - High magnification SEM image of the crack present in the diffusion barrier. The defect appears to be the result of the foil shearing process pre-HII as an interaction layer has formed along the fuel foil-to-diffusion barrier interface.

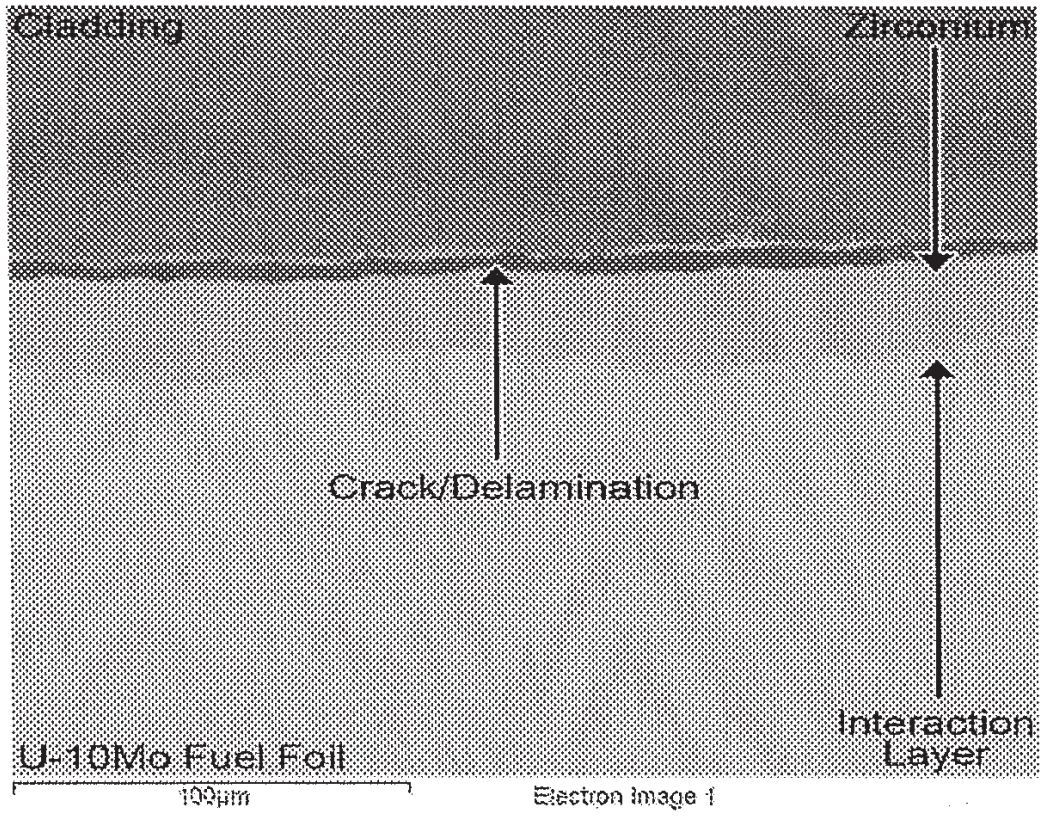

Figure 28: BM814-F10, 500x-BSE - SEM image of a crack/delamination between the zirconium diffusion barrier and the cladding. 


\section{CONCLUSIONS}

Two archival fuel plates were analyzed as part of the AFIP-6 characterization effort at INL. The summary of the findings is below:

- The cladding-to-cladding bonding was normal with no indication of a poor bond.

- The preformed oxide layer on the cladding was within the normal range.

- A silicon rich interaction layer formed along the zirconium diffusion barrier-to-cladding interface. This interaction layer is thicker than previous experiments.

- At least three interaction layers formed between the zirconium and the U-10Mo fuel foil. These interaction layers are normal for monolithic fuel foils.

- Carbides, oxides, and decomposition were observed in the fuel foil. There were more of these second phase defects observed in this experiment than in previous AFIP-3 and RERTR-10A experiments.

- The fuel foil exhibits duplex size grains instead of equi-axial grains as found in AFIP-3 and RERTR-10A. Some large and elongated grains of more than $100 \mu \mathrm{m}$ in size were observed.

- The carbon concentration of the fuel foil was higher than that of AFIP-3 and AFIP-4.

- The uncovered fuel foil ends exhibit a significant amount of interaction. The interaction layer formed is greater than $100 \mu \mathrm{m}$ in size.

- The zirconium diffusion barrier and cladding also exhibited an increased interaction area at the end of the fuel zone.

- Some cracking was found in the interaction layer, but this is most likely due to sample preparation or foil shearing. These interaction products are brittle and need to be monitored closely.

\section{REFERENCES}

1. PLN-3222, "AFIP-6 Experiment Control Plan"

2. INL/LTD-11-21655, "AFIP-6 Fabrication Summary Report" 